\title{
Stabilization of Factor VIII in Plasma by the von Willebrand Factor
}

\author{
STUDIES ON POSTTRANSFUSION AND DISSOCIATED FACTOR VIII AND
}

IN PATIENTS WITH VON WILLEBRAND'S DISEASE

\author{
Harvey J. Weiss, Ira I. Sussman, and Leon W. Hoyer \\ From the Department of Medicine (Division of Hematology), The Roosevelt Hospital and \\ Columbia University College of Physicians and Surgeons, New York, 10019, the \\ Division of Hematology, Queens General Hospital-Long Island Jewish \\ Medical Center, Jamaica, New York 11432, and the University of \\ Connecticut School of Medicine, Farmington, Connecticut 06032
}

\begin{abstract}
A B S TRACT In normal plasma, the ratio of the procoagulant activity of factor VIII $\left(\mathrm{VIII}_{\mathrm{AHF}}\right)$ to that of the von Willebrand factor activity (ristocetin cofactor, $\mathrm{VIII}_{\mathrm{VWF}}$ ) or factor VIII antigen $\left(\mathrm{VIII}_{\mathrm{AGN}}\right)$ is $\sim 1$, but ratios $>1$ (e.g., VIII $_{\mathrm{AHF}}>\mathrm{VIII}_{\mathrm{VWF}}$ or $\mathrm{VIII}_{\mathrm{AGN}}$ ) may be observed in some patients with von Willebrand's disease and in the "late" posttransfusion plasmas of patients with this disorder. The lability of $\mathrm{VIII}_{\mathrm{AHF}}$ was studied by incubating plasma, diluted 1:10 in imidazole buffer $\mathrm{pH} 7.1$, for $6 \mathrm{~h}$ at $37^{\circ} \mathrm{C}$. With normal plasmas, $77 \pm 12 \%$ (SD) of the original $\mathrm{VIII}_{\mathrm{AHF}}$ activity remained after incubation. $\mathrm{VIII}_{\mathrm{AHF}}$ was labile (e.g., $35-55 \%$ residual activity) in the "late" posttransfusion plasmas $\left(\mathrm{VIII}_{\mathrm{AHF}} \gg \mathrm{VIII}_{\mathrm{VWF}}\right)$ of a patient with von Willebrand's disease, but not in the "early" posttransfusion plasmas $\left(\mathrm{VIII}_{\mathrm{AHF}} \sim \mathrm{VIII}_{\mathrm{VWF}}\right)$. $\mathrm{VIII}_{\mathrm{AHF}}$ was also labile in the (base-line) plasmas of three patients with von Willebrand's disease in whom the ratios of VIII $_{\mathrm{AHF}}$ to VIII $_{\mathrm{VWF}}$ were 4.4 to 8.1 , but not in the plasmas of four other patients in whom the ratio was $\sim 1$. The electrophoretic mobility of factor VIII antigen was increased in two of the three patients with labile VIII ${ }_{\mathrm{AHF}}$. In both of these patients, and in the late posttransfusion plasmas, labile VIII $_{\mathrm{AHF}}$ activity could be stabilized by the addition of purified von Willebrand factor (lacking VIII $_{\mathrm{AHF}}$ activity) or by hemophilic plasma, but not by plasmas of patients with severe von Willebrand's disease. Thus, VIII $\mathrm{VwF}_{\mathrm{vw}}$ may serve to stabilize VIII $_{\mathrm{AHF}}$ and this might explain the posttransfusion findings in von Willebrand's disease.
\end{abstract}

Received for publication 20 December 1976 and in revised form 16 March 1977.

\section{INTRODUCTION}

Recent studies suggest that factor VIII is a macromolecule, or macromolecular complex, having two biologic functions. One activity of factor VIII corrects the clotting defect in hemophilia (antihemophilic factor, AHF, or VIII ${ }_{\mathrm{AHF}}$ activity); ${ }^{1}$ another corrects defects of platelet function in von Willebrand's disease $(1,2)$. The levels of these two activities in plasma can be quantified by biologic assays in which the activity of pooled normal plasma is designated as $100 \%$ activity. In normal plasmas, the ratio of these two activities is generally close to $1.0(3,4)$. However, under various circumstances, the levels of these activities can be "dissociated." One type of dissociation is often seen in patients with von Willebrand's disease who have been transfused with normal plasma or cryoprecipitate; characteristically, the level of VIII $_{\mathrm{AHF}}$ may remain increased when that of the von Willebrand factor $\left(\mathrm{VIII}_{\mathrm{VWF}}\right)$, and factor VIII antigen $\left(\mathrm{VIII}_{\mathrm{AGN}}\right)$, has returned to low values $(5,6)$. Injection of epinephrine into some patients with this disorder may also result in a disproportionate increase in $\mathrm{VIII}_{\mathrm{AHF}}$ levels (7). Another type of dissociation has been observed in some patients with von Willebrand's disease who show levels of VIII $_{A H F}$ that are relatively higher than those for $\mathrm{VIII}_{\mathrm{VWF}}(3,4,8-10)$ or both $\mathrm{VIII}_{\mathrm{VWF}}$ and $\mathrm{VIII}_{\mathrm{AGN}}$

\footnotetext{
${ }^{1}$ Abbreviations used in this paper: C/S, cryoprecipitate supernate ratio of VIII $_{\mathrm{AHF}}$; STI, soybean trypsin inhibitor;

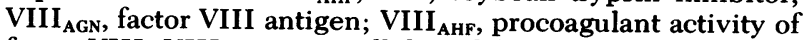
factor VIII; VIII $I_{\mathrm{VWF}}$, von Willebrand factor VIII activity.
} 
$(3,11,12)$. Finally, the two biologic activities of normal factor VIII can be dissociated under conditions of high ionic strength, the activity of $\mathrm{VIII}_{\mathrm{AHF}}$ appearing with those of lower molecular weight proteins, while that of $\mathrm{VIII}_{\mathrm{VWF}}$ retains its high molecular weight characteristics $(4,6,13-18)$. In this study, we present evidence that in all the above circumstances, the activity of $\mathrm{VIII}_{\mathrm{AHF}}$ is relatively more labile and can be stabilized by the addition of the von Willebrand factor, or by hemophilic plasma which contains von Willebrand factor activity. By contrast, no stabilization was obtained with plasma of patients with severe von Willebrand's disease. This stabilizing effect of the von Willebrand factor may have implications regarding the pathogenesis of the latter disorder.

\section{METHODS}

\section{Nomenclature and assay of the factor VIII complex}

The biologic components of the factor VIII complex are referred to as the antihemophilic factor (AHF) and the von Willebrand factor (VWF) and their respective activities are designated as follows: VIII $\mathrm{AHF}_{\mathrm{AF}}$ is the procoagulant activity of factor VIII that corrects the coagulation defect in hemophilia, as measured by a one-stage method using the kaolinactivated partial thromboplastin time (3) and a Sherwood Lancer Coagulizer (Sherwood Medical Industries, Inc., St. Louis, Mo.) to read the end point; VIII $\mathrm{VWF}_{\mathrm{VW}}$ is the activity of factor VIII in plasma that is required for ristocetin-induced platelet aggregation, assayed by a washed platelet system described previously (3). Factor VIII antigen, or VIII $\mathrm{AGN}$, is the antigen present in human plasma recognized by an antibody to human factor VIII and quantified by radioimmunoassay (19). The minimal sensitivities of these assays of these three components of the factor VIII complex are 1,3 , and 0.3 $\mathrm{U} / 100 \mathrm{ml}$, respectively.

\section{Preparation and storage of plasma}

Venous blood was collected with $1 / 10$ vol of $3.2 \%$ sodium citrate in polypropylene tubes (Ivan Sorvall, Inc., Norwalk, Conn.) and centrifuged at $2,400 \mathrm{~g}$ and $4^{\circ} \mathrm{C}$ for $30 \mathrm{~min}$. The platelet-poor plasma was removed and assayed for VIII $_{\mathrm{AHF}}$ activity against pooled normal plasma, as previously described (3). Aliquots were frozen at $-70^{\circ} \mathrm{C}$ for subsequent determination of VIII $_{\mathrm{VWF}}$ and $\mathrm{VIII}_{\mathrm{AGN}}$.

\section{Buffers}

One part of a stock solution of $0.25 \mathrm{M}$ imidazole of varying $\mathrm{pH}$ value was mixed with either four parts of normal saline (0.05 $\mathrm{M}$ imidazole-saline), nine parts of saline $(0.025 \mathrm{M}$ imidazole-saline), or nine parts of distilled water $(0.025 \mathrm{M}$ imidazole).

\section{Determination of $\mathrm{VIII}_{\mathrm{AHF}}$ stability}

The stability of VIII $_{\mathrm{AHF}}$ activity at $37^{\circ} \mathrm{C}$ was determined by incubating plasma, diluted $1: 10$ in $0.05 \mathrm{M}$ imidazole-saline buffer for varying periods of time in polystyrene tubes (Falcon Plastics, Div. BioQuest, Oxnard, Calif.) and deter- mining VIII $_{\mathrm{AHF}}$ values (without further dilution) on the incubated specimens. The dependence of VIII $_{\mathrm{AHF}}$ stability on $\mathrm{pH}$ was determined by making the initial dilutions in buffers of varying $\mathrm{pH}$, incubating for $4 \mathrm{~h}$, and determining the residual VIII $_{\mathrm{AHF}}$ activity. Time-dependent VIII $_{\mathrm{AHF}}$ stability was determined with imidazole-saline buffer of $\mathrm{pH} 7.1$ as the initial diluent and incubating for $0,1,2,4$, and $6 \mathrm{~h}$. (The $\mathrm{pH}$ of the plasma-buffer mixtures did not differ by more than $0.04 \mathrm{pH} U$ from that of the buffer alone.) The VIII activity in the incubated specimen was assayed and then expressed as a percentage of the initial (zero time) activity. In several studies, the buffer that was used to dilute the plasmas contained $0.1 \%$ sodium azide in order to eliminate the possibility that the lability of VIII $_{\mathrm{AHF}}$ might be the result of bacterial growth and proteolysis during the incubation period.

\section{Cryoprecipitability of $\mathrm{VIII}_{A H F}$}

In preliminary studies on normal plasma, we found the following method yielded the maximum amount of $\mathrm{VIII}_{\mathrm{AHF}}$ in the cryoprecipitate and the maximum total recovery (cryoprecipitate plus supernate). A $12 \times 75-\mathrm{mm}$ polypropylene tube (Falcon Plastics) containing $2 \mathrm{ml}$ of fresh plasma was placed in $\mathrm{a}-70^{\circ} \mathrm{C}$ freezer and kept there for at least $18 \mathrm{~h}$. (Storage for up to 10 days did not affect the results.) The tube containing the frozen plasma was immersed in an ice bath and kept in a refrigerator for $3 \mathrm{~h}$, after which time it was centrifuged at $2,400 \mathrm{~g}$ and $4^{\circ} \mathrm{C}$ for $15 \mathrm{~min}$. The supernate was removed and the cryoprecipitate was dissolved in a total volume of $2 \mathrm{ml}$ of $0.05 \mathrm{M}$ imidazole-saline buffer, $\mathrm{pH} 7.1$ at $37^{\circ} \mathrm{C}$. Both supernate and cryoprecipitate were then diluted 1:5 and assayed for $\mathrm{VIII}_{\mathrm{AHF}}$. In 11 normal subjects, the ratio of $\mathrm{VIII}_{\mathrm{AHF}}$ activity in cryoprecipitate to that in the supernate was $3.7 \pm 1.4$ (SD). Recovery of the initial plasma $\mathrm{VIII}_{\mathrm{AHF}}$ activity in the cryoprecipitate and supernate was $90 \pm 15 \%$.

\section{Preparation of purified von Willebrand factor devoid of $\mathrm{VIII}_{A H F}$ activity}

A commercially available, semipurified factor VIII preparation material (Hemofil Method Four, Hyland Div., Travenol Laboratories, Inc., Costa Mesa, Calif.) was dissolved in $0.025 \mathrm{M}$ imidazole buffer, $\mathrm{pH} 7.1$ containing $0.25 \mathrm{M} \mathrm{CaCl}$.

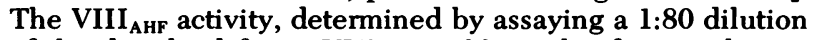
of the dissolved factor VIII, was $36 \mathrm{U} / \mathrm{ml}$. After incubation at room temperature for $30 \mathrm{~min}, 3.8 \mathrm{ml}$ (137 U VIII $\mathrm{AHF}_{\text {HF }}$ were applied to a siliconized column, $1.6 \times 28 \mathrm{~cm}$, of $4 \%$ agarose (Bio-Gel A-15m, Bio-Rad Laboratories, Richmond, Calif.) and eluted with imidazole buffer containing $0.25 \mathrm{M}$ $\mathrm{CaCl}_{2}$ at $100 \mathrm{~mm} \mathrm{H}_{2} \mathrm{O}$ outlet pressure and a flow rate of $0.15 \mathrm{ml} / \mathrm{min}$. Under these conditions of high calcium concentration $(13,18,20), 57 \%$ of the applied VIII $_{\mathrm{AHF}}$ was recovered from the column; $2 \%$ of the recovered activity appeared in the void volume, while the remaining activity eluted with proteins of lower molecular weight. The void volume fractions were rechromatographed on a $1.6 \times 27-\mathrm{cm}$ column containing Bio-Gel A-15m packed in $0.025 \mathrm{M}$ imidazole buffer, but lacking $\mathrm{CaCl}_{2}$. Elution was carried out with imidazole-saline and the first fraction that showed $\mathrm{OD}_{280}$ (Buchler Fructoscan, Buchler Instruments Div., Scarle Analytic Inc., Fort Lee, N.J.) activity was removed and used in stabilization studies to be described. This fraction was devoid of any VIII $_{A H F}$ activity but contained von Willebrand activity (see Table I). A lyophilized sample was dissolved in $0.01 \mathrm{M}$ sodium phosphate buffer, $\mathrm{pH} 7.0$, containing $1 \%$ 
TABLE I

Characteristics of Posttransfusion Plasmas of a Patient with "Severe" von Willebrand's Disease

\begin{tabular}{|c|c|c|c|c|c|c|c|}
\hline \multirow[b]{2}{*}{ Study } & \multirow{2}{*}{$\begin{array}{l}\text { Time } \\
\text { after } \\
\text { trans- } \\
\text { fusion }\end{array}$} & \multirow{2}{*}{$\begin{array}{c}\text { Addition } \\
\text { plasma } \\
\text { (in vitro) }\end{array}$} & \multicolumn{3}{|c|}{ Factor VIII complex } & \multicolumn{2}{|c|}{$\begin{array}{l}\text { Cryopre- } \\
\text { cipitability } \\
\text { of VIII }_{\text {AHF }}{ }^{*}\end{array}$} \\
\hline & & & AHF & VWF & AGN & $\begin{array}{l}\text { Cryol } \\
\text { Supt }\end{array}$ & $\begin{array}{c}\text { Re- } \\
\text { covery }\end{array}$ \\
\hline & $h$ & & & $U / 100$ & & Ratio & $\%$ \\
\hline \multirow[t]{7}{*}{ I } & pre & - & $<1$ & $<3$ & $<0.3$ & - & - \\
\hline & 1 & - & 29 & 39 & 27 & 0.9 & 79 \\
\hline & 5 & - & 42 & 37 & - & 1.0 & 95 \\
\hline & 24 & - & 40 & 6 & 8 & 0.7 & 107 \\
\hline & 48 & - & 28 & $<3$ & 3 & 0.4 & 64 \\
\hline & 48 & buffer & 27 & $<3$ & - & 0.3 & 85 \\
\hline & 48 & VWF & 27 & 51 & 69 & 1.1 & 81 \\
\hline \multirow[t]{5}{*}{ II\$ } & pre & - & $<1$ & $<3$ & 0.3 & - & - \\
\hline & 5 & - & 175 & 128 & 122 & 1.5 & 80 \\
\hline & 30 & - & 140 & 66 & 56 & 1.8 & 96 \\
\hline & 54 & - & 100 & 36 & 26 & 0.8 & 96 \\
\hline & 78 & - & 95 & 21 & 22 & 0.6 & 60 \\
\hline
\end{tabular}

IU of cryoprecipitate is that obtained from $1 \mathrm{U}(500 \mathrm{ml})$ of blood.

* Ratio of $\mathrm{VIII}_{\mathrm{AHF}}$ in cryoprecipitate (cryo) to that in supernate (supt) and percentage of initial plasma activity recovered (in cryo + supt).

$\ddagger$ In transfusion study I, patient (V.M.) received $12 \mathrm{U}$ of normal cryoprecipitate. The 48-h posttransfusion specimen was also studied after addition of purified von Willebrand factor (VWF) or buffer.

$\$$ In transfusion study II, the patient received $113 \mathrm{U}$ of cryoprecipitate over a 6-day period. Specimens were obtained at various intervals after the last transfusion.

sodium dodecyl sulfate (SDS). Reduction was carried out in $1.0 \% \beta$-mercaptoethanol at $56^{\circ} \mathrm{C}$ for $2 \mathrm{~h}$. Electrophoresis of the unreduced sample in a 5\% acrylamide gel (bisacrylamide/ total acrylamide $=0.027$ ) containing $0.1 \%$ SDS at $8 \mathrm{~mA}$ per tube for $4 \mathrm{~h}$ failed to disclose the presence of any protein (detectable by Coomassie Blue staining) that entered the gel (Fig. 1 A). Electrophoresis of the reduced sample disclosed the presence of a single faintly stained protein that entered the gel (Fig. 1 B) and had an apparent molecular weight (21) of about 222,000 , estimated by comparison with the following markers (Sigma Chemical Co., St. Louis, Mo.): ribonuclease (mol wt 13,700), chymotrypsinogen (mol wt 25,700), egg albumin (mol wt 43,000), serum albumin (mol wt 68,000), and cold insoluble globulin (mol wt 420,000 unreduced and 210,000 reduced, kindly supplied by Dr. Michael Mosesson, Downstate Medical Center, State University of New York, Brooklyn, N. Y.). The estimated molecular weight of the von Willebrand factor is similar to previously reported values for factor VIII (22-27).

\section{Preparation of low molecular weight factor VIII containing VIII ${ }_{A H F}$ but no VIII ${ }_{V W F}$ activity}

Hemofil $(250 \mathrm{mg}$ ) was dissolved in $3.5 \mathrm{ml}$ of $0.025 \mathrm{M}$ imidazole-saline, $\mathrm{pH} 7.2$ containing soy bean trypsin inhibitor
(STI, $0.1 \mathrm{mg} / \mathrm{ml}$ ) and $10^{-3} \mathrm{M}$ benzamidine HCL and chromatographed on a $2.6 \times 40-\mathrm{cm}$ column packed with Bio-Gel A-15m to a height of $28.5 \mathrm{~cm}$. Elution was performed with imidazole-saline buffer containing STI and benzamidine at the above concentrations at a flow rate of $0.45 \mathrm{ml} / \mathrm{min}$; fractions $(4.1 \mathrm{ml})$ were collected by a drop counter. The eluate was continuously monitored for $\mathrm{OD}_{280}$ and the first fraction containing detectable protein was removed. After the addition of anhydrous $\mathrm{CaCl}_{2}$ to a final concentration of $0.25 \mathrm{M}$, the fraction was incubated for $30 \mathrm{~min}$ at room temperature, and then applied to a column (as above) packed with Bio-Gel A-15m. The buffer used to equilibrate and elute the column contained STI, benzamidine, and $\mathrm{CaCl}_{2}$ (in the above concentrations). Fractions in which $\mathrm{VIII}_{\mathrm{AHF}}$ activity was anticipated (from previous studies) were pooled, applied to small columns packed with Sephadex G-75, and eluted with $0.025 \mathrm{M}$ imidazole-saline. Aliquots of $2 \mathrm{ml}$ were collected and assayed for $\mathrm{VIII}_{\mathrm{AHF}}$; the fractions showing VIII $_{\mathrm{AHF}}$ activity were pooled and used as the source of low molecular weight factor VIII. VIII $\mathrm{VWF}_{\mathrm{V}}$ activity was undetectable in these fractions.

\section{Chromatography of plasma on Bio-Gel A-15m}

$8 \mathrm{ml}$ of plasma were applied through a flow adapter to the top of a $2.6 \times 40-\mathrm{cm}$ siliconized glass column packed to a height of $28.5 \mathrm{~cm}$ with Bio-Gel A-15m that had been previously equilibrated with $0.025 \mathrm{M}$ imidazole-saline, $\mathrm{pH} 7.1$,

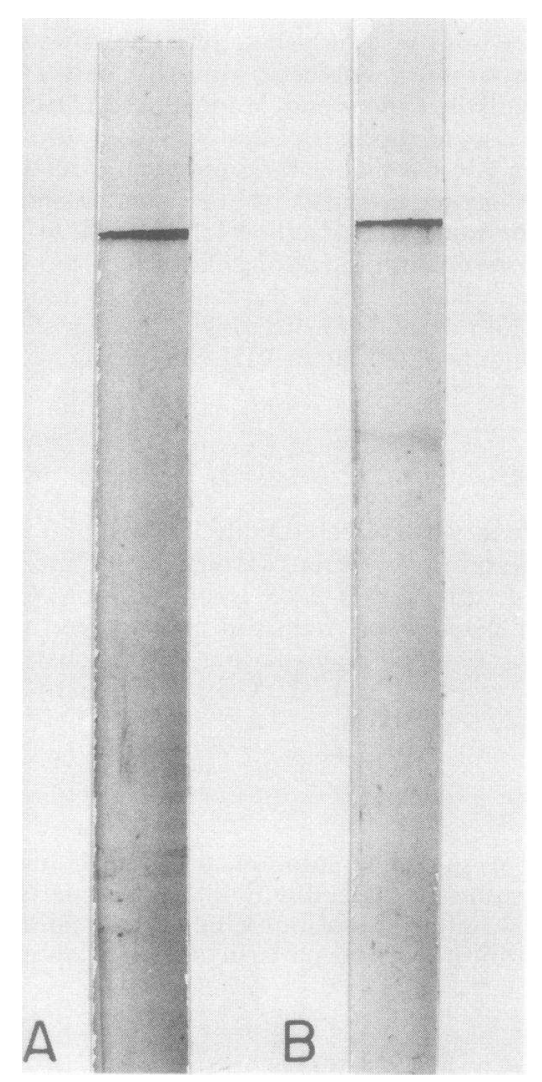

FIGURE 1 Electrophoresis of purified von Willebrand factor on SDS-polyacylamide gel. The gel on the left $(1 \mathrm{~A})$ was obtained with an unreduced sample; the sample on the right (1 B) was obtained after reduction with $\beta$-mercaptoethanol. 
containing $0.1 \%$ bovine albumin (Sigma Chemical). A flow rate of $0.7 \mathrm{ml} / \mathrm{min}$ was maintained by means of a Mariotte flask using an outlet pressure of $100 \mathrm{~cm} \mathrm{H}_{2} \mathrm{O}$. The amount of VIII $_{\mathrm{AHF}}$ in each fraction was determined from a standard curve constructed by diluting control plasma in imidazolesaline buffer containing $0.1 \%$ bovine albumin, and the activity in each fraction was expressed as a percent of the total recovered VIII $_{\mathrm{AHF}}$ activity. The elution pattern of $\mathrm{VIII}_{\mathrm{AHF}}$ was characterized by calculating the VIII $_{\mathrm{AHF}}$ activity recovered in three summed fractions: I was the total activity in fractions $11-14$, the first four fractions in which $\mathrm{OD}_{280}$ was detectable; II was the activity in fractions 15-18; III was the activity in fractions 19-22. In seven normal plasmas, the percents of the total VIII $_{\mathbf{A H F}}$ activity recovered in pools I, II, and III were $84.1 \pm 6(\mathrm{SD}), 8.36 \pm 1.3$, and $3.57 \pm 1.14 \%$, respectively.

\section{Mobility of factor VIII-related antigen on crossed immunoelectrophoresis}

This was carried out in $0.9 \%$ agarose (Indubiose A37) using $5 \times 7.5-\mathrm{cm}$ glass slides. The buffer used for the preparation of the agarose and in the reservoirs was $0.025 \mathrm{M}$ barbital, $\mathrm{pH}$ 9.5. Approximately $1 \mu$ l of Evan's blue dye was added to 30 $\mu \mathrm{l}$ of plasma in a $5-\mathrm{mm}$ well before electrophoresis at $8 \mathrm{~V} / \mathrm{cm}$ (46 $\mathrm{mA}$ ) for $1 \mathrm{~h}$ in a water-cooled electrophoresis chamber. The migration of Evans blue dye bound to albumin was measured $(3.75-4.00 \mathrm{~cm})$ before the agarose was removed from the top three-quarters of the slide and replaced by $4 \mathrm{ml}$ of $0.9 \%$ of agarose containing a 1:500 dilution of rabbit antifactor VIIIrelated antigen (19). Electrophoresis of the proteins into the agarose containing antibody was carried out at a constant current $(1.8 \mathrm{~mA} / \mathrm{cm})$ for $20 \mathrm{~h}$ in the water-cooled chamber. The plate was then rinsed briefly in $0.5 \mathrm{M} \mathrm{NaCl}, 0.05 \mathrm{M}$ phosphate, $\mathrm{pH} 7.2$, and in distilled water before drying and staining with Coomassie Blue (28). VIII $_{\mathrm{AGN}}$ mobilities of plasmas are expressed as a ratio of the migration distance of the peak of the immunoprecipitate from the origin divided by the migration distance of albumin in that plasma. In order to concentrate plasmas with very low content of factor VIII-related antigen, an equal volume of $20 \%$ ethylene glycol 6,000 (J. T. Baker Chemical Co., Phillipsburg, N.J.) was first added. After continuous mixing for $1 \mathrm{~h}$ at $4^{\circ} \mathrm{C}$, the precipitate was separated by centrifugation at $3,000 \mathrm{~g}$ for $20 \mathrm{~min}$ at $4^{\circ} \mathrm{C}$. The precipitated proteins were dissolved in the barbital buffer (1/10 of the original plasma volume was added; the concentration of antigen in the dissolved precipitate was five times that of the starting plasma). In studies on five normal subjects, the average crossed immunoelectrophoresis mobility of factor VIII antigen in frozen plasma was found to be $97 \%$ (range $84-113 \%$ ) of that in polyethylene glycol concentrate obtained from that plasma.

\section{Plasmas used in study}

Transfusion studies. A 31-yr-old female patient (V.M.) with severe von Willebrand's disease (bleeding time $>60$ min) was transfused on three separate occasions. On the first occasion, she received $12 \mathrm{U}$ of cryoprecipitate because of bleeding into her left knee, right elbow and right ankle, and a recurrence of gingival bleeding (transfusion I). 9 mo later, she received $113 \mathrm{U}$ of cryoprecipitate over a 6-day period as treatment for gastrointestinal bleeding from an undisclosed site (transfusion II). Plasmas for study were obtained at various intervals after the last dose of cryoprecipitate. Values of the factor VIII complex in these plasmas are shown in Table I and are discussed further in Results. 2 mo after transfusion II, she was given $167 \mathrm{U}$ of cryoprecipitate (transfusion III) over a 7-day period because of another episode of gastrointestinal bleeding. Values of the factor VIII complex in the posttransfusion plasma, as well as the results of other studies that are discussed later (see Results), are shown in Table II.

Patients with "mild" von Willebrand's disease. Seven patients with the typical findings of a prolonged bleeding time and decreased levels of the factor VIII complex (Table III) were studied. Levels of $\mathrm{VIII}_{\mathrm{AHF}}$ activity in these patients ranged from $30-50 \mathrm{U} / 100 \mathrm{ml}$, levels of $\mathrm{VIII}_{\mathrm{VwF}}$ were $6-46$ $\mathrm{U} / 100 \mathrm{ml}$, and those of $\mathrm{VIII}_{\mathrm{AGN}}$ were $2-43 \mathrm{U} / 100 \mathrm{ml}$.

TABLE II

VIII $_{A H F}$-Elution Pattern and Factor VIII Antigen Mobility of (VIII ${ }_{A H F}$-Labile) Posttransfusion Plasmas

\begin{tabular}{|c|c|c|c|c|c|c|c|c|c|c|}
\hline \multirow{2}{*}{$\begin{array}{l}\text { Time after } \\
\text { transfusion }\end{array}$} & \multicolumn{3}{|c|}{ Factor VIII complex } & \multirow{2}{*}{$\begin{array}{c}\text { VIII }_{\text {AHF }} \text { stability } \\
\text { in vitro, initial } \\
\text { activity }\end{array}$} & \multirow{2}{*}{$\begin{array}{c}\text { VIII }_{\mathrm{AHF}} \\
\text { activity re- } \\
\text { covered in chromato- } \\
\text { graphic fractions }\end{array}$} & \multicolumn{4}{|c|}{$\begin{array}{l}\text { Elution pattern, } \\
\text { recovered activity* }\end{array}$} & \multirow{2}{*}{$\begin{array}{l}\text { Relative mobility } \\
\text { of VIII }\end{array}$} \\
\hline & AHF & VWF & AGN & & & $\mathbf{I}$ & II & III & $\mathbf{R}$ & \\
\hline$h$ & \multicolumn{3}{|c|}{$\mathrm{U} / 100 \mathrm{ml}$} & $\%$ & $\%$ & \multicolumn{4}{|c|}{$\%$} & \\
\hline \multicolumn{11}{|l|}{$\begin{array}{r}\text { Patient V.M. } \\
\text { (study III) }\end{array}$} \\
\hline 3 & 160 & 86 & 83 & 61 & 79 & 72 & 17 & 7 & 4 & 0.33 \\
\hline 24 & 97 & 60 & 74 & 62 & - & 一 & - & - & 一 & 0.37 \\
\hline 48 & 85 & 38 & 45 & 59 & - & - & - & - & 一 & 0.41 \\
\hline 72 & 82 & 16 & 22 & 37 & 69 & 62 & 22 & 8 & 8 & - \\
\hline 79 & 73 & 6 & 20 & 38 & - & - & 一 & - & 一 & - \\
\hline 96 & 50 & 4 & 12 & 39 & 52 & 53 & 26 & 18 & 3 & - \\
\hline Normal subjects & \multicolumn{3}{|c|}{$(n=20) \ddagger$} & $(n=11)$ & & \multicolumn{4}{|c|}{$(n=7)$} & $(n=11)$ \\
\hline mean & 92 & 95 & 103 & 77 & 72 & 84 & 8 & 4 & 4 & 0.32 \\
\hline SD & 18 & 20 & 29 & 12 & 17 & 3 & 1 & 1 & 2 & 0.015 \\
\hline
\end{tabular}

* $\mathrm{VIII}_{\mathrm{AHF}}$ in fractions 11-14 (I), 15-18 (II), 19-22 (III), and the remainder (R) of the fractions eluted after chromatography of plasma on Bio-gel A-15m, expressed as percent of the recovered activity.

$\ddagger$ Data from previous study (3). 
TABLE III

Characteristics of Plasmas in Patients with "Mild" von Willebrand's Disease

\begin{tabular}{|c|c|c|c|c|c|c|c|c|c|c|c|}
\hline \multirow[b]{2}{*}{ Source } & \multicolumn{3}{|c|}{ Factor VIII complex } & \multirow{2}{*}{$\begin{array}{c}\mathrm{VIII}_{\mathrm{AHF}}^{\text {activity }} \\
\text { recovered in } \\
\text { chromatographic } \\
\text { fractions }\end{array}$} & \multicolumn{4}{|c|}{$\begin{array}{l}\text { Elution pattem, } \\
\text { recovered activity }\end{array}$} & \multirow{2}{*}{$\begin{array}{l}\text { Relative mobility } \\
\text { of VIII }\end{array}$} & \multicolumn{2}{|c|}{$\begin{array}{l}\text { Cryoprecipitability } \\
\text { of VIII } \text { AHF }^{*}\end{array}$} \\
\hline & AHF & VWF & AGN & & I & II & III & $\mathbf{R}$ & & Cryo/Supt & Recovery \\
\hline & \multicolumn{3}{|c|}{$\mathrm{U} / 100 \mathrm{ml}$} & $\%$ & \multicolumn{4}{|c|}{$\%$} & & Ratio & $\%$ \\
\hline \multicolumn{12}{|l|}{ von Willebrand's } \\
\hline Z.D. & 33 & 26 & 27 & 48 & 82 & 8 & 6 & 4 & 0.36 & 1.5 & 79 \\
\hline E.D. & 50 & 36 & 30 & 77 & 82 & 9 & 4 & 5 & 0.34 & 1.8 & 78 \\
\hline S.B. & 45 & 40 & 30 & 69 & 77 & 9 & 6 & 9 & 0.33 & 1.5 & 60 \\
\hline W.G. & 40 & 46 & 43 & - & - & - & - & - & 0.34 & 2.2 & 47 \\
\hline J.M. & 35 & 8 & 5 & - & - & - & - & - & 0.29 & 0.3 & 87 \\
\hline J.L. & 33 & 7 & 15 & 66 & 56 & 18 & 10 & 16 & 0.42 & 1.0 & 74 \\
\hline A.S. & 30 & 6 & 2 & 46 & 71 & 12 & 7 & 10 & 0.40 & 0.1 & 90 \\
\hline Normal subjects & \multicolumn{3}{|c|}{$(n=20) \S$} & \multicolumn{5}{|c|}{$(n=7)$} & $(n=6)$ & \multicolumn{2}{|c|}{$(n=11)$} \\
\hline mean & 92 & 95 & 103 & 72 & 84 & 8 & 4 & 4 & 0.32 & 3.7 & 90 \\
\hline SD & 18 & 20 & 29 & 17 & 3 & 1 & 1 & 2 & 0.015 & 1.3 & 15 \\
\hline
\end{tabular}

${ }^{*}$ Ratio of $\mathrm{VIII}_{\mathrm{AHF}}$ in cryoprecipitate (cryo) to that in supernate (supt) and percentage of initial plasma activity recovered (in cryo + supt).

$\$$ VIII $_{\mathrm{AHF}}$ in fractions 11-14 (I), 15-18 (II), 19-22 (III), and the remainder (R) of the fractions eluted after chromatography of plasma ion Bio-gel A-15m, expressed as percent of the recovered activity.

$\S$ Data from previous study (3).

Normal subjects. Plasmas from healthy hospital employees were used as controls.

\section{Other plasmas used in study}

Plasmas of four patients with severe hemophilia $\left(\mathrm{VIII}_{\mathrm{AHF}}\right.$ deficiency) were used as a source of von Willebrand factor in some studies. As controls for these studies, we used plasmas from three patients with severe von Willebrand's disease. The values of the factor VIII complex in these seven patients are shown in Table IV.

\section{RESULTS}

Stability of VIII ${ }_{A H F}$ in normal plasmas. In preliminary studies, incubation of plasma from 16 normal subjects for $4 \mathrm{~h}$ in buffers of varying $\mathrm{pH}$ values showed that VIII $\mathrm{AHF}_{\mathrm{AH}}$ activity was best maintained in the $\mathrm{pH}$ range of 6.9-7.25 (Fig. $2 \mathrm{~A}$ ), similar to findings in previous studies $(29,30)$. For determining sequential loss of VIII $_{\mathrm{AHF}}$ activity in plasma during incubation at $37^{\circ} \mathrm{C}$, we elected to use a buffer of $\mathrm{pH}$ 7.1. The sequential loss of activity in normal plasma during 6 $h$ of incubation at this $\mathrm{pH}$ value is shown in Fig. $2 \mathrm{~B}$ and shows that $77 \pm 12 \%$ (SD) of the initial activity remained in the plasma after $6 \mathrm{~h}$ of incubation.

Increased lability of $\mathrm{VIII}_{A H F}$ in late posttransfusion plasmas, corrected by von Willebrand factor. The levels of the factor VIII complex in the plasma of patient V.M. at varying intervals after transfusion of cryoprecipitate on two separate occasions (studies I and II) are shown in Table I. They demonstrate the type of dissociation reported in previous studies: the $\mathrm{VIII}_{\mathrm{AHF}}$ levels remained increased, while those for $\mathrm{VIII}_{\mathrm{VWF}}$ and VIII $_{A G N}$ were declining. In transfusion study $I$, the levels of VIII $\mathrm{AHF}_{\text {in }}$ the 1-h and 48-h posttransfusion samples were almost identical $(29$ and $28 \mathrm{U} / 100 \mathrm{ml}$, respectively). However, $\mathrm{VIII}_{\mathrm{VWF}}$ and $\mathrm{VIII}_{\mathrm{AGN}}$ levels in the $1-\mathrm{h}$ posttransfusion plasma were 39 and $27 \mathrm{U} / 100$ $\mathrm{ml}$, whereas the levels in the 48 -h plasma were $<3$ and $3 \mathrm{U} / 100 \mathrm{ml}$, respectively, for these factors. The stability of $\mathrm{VIII}_{\mathrm{AHF}}$ activity in these two plasmas were studied on aliquots that had been frozen at $-70^{\circ} \mathrm{C}$ for $5-10$ days. (VIII $_{\mathrm{AHF}}$ values on these stored plasma specimens were

TABLE IV

Plasmas Used in Correction Studies

\begin{tabular}{cccc}
\hline & & \multicolumn{2}{c}{ Factor VIII complex } \\
\cline { 2 - 3 } & AHF $\quad$ VWF $\quad$ AGN \\
\hline
\end{tabular}

Severe von Willebrand's disease

$\begin{array}{lrrr}\text { C.M. } \square & 2 & <3 & <0.3 \\ \text { D.R. } \triangle & 2 & <3 & <0.3 \\ \text { V.M. } \triangle & <1 & <3 & <0.3 \\ \text { Hemophilia } & & & \\ \text { J.R. } & <1 & 128 & 127 \\ \text { M.R.* } & <1 & 95 & 106 \\ \text { P.R.* } & <1 & 112 & 123 \\ \text { M.B. } \nabla & <1 & 165 & 198\end{array}$

Symbols are those depicted for the plasmas of these patients used in experiments shown in Figs. 4, 8, 9, and 10.

* P.R. and M.R. are brothers, unrelated to J.R. and M.B. 

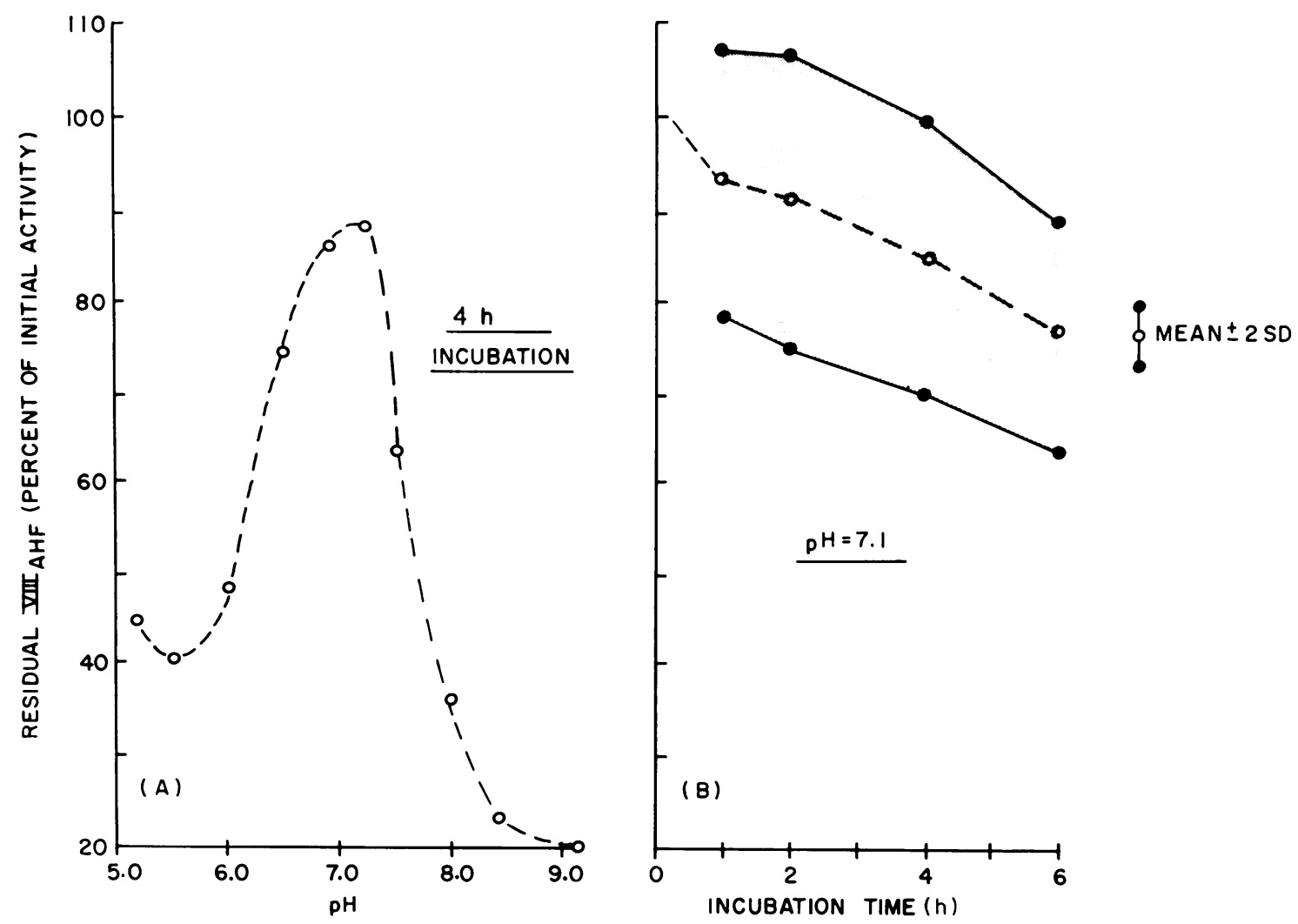

FIGURE 2 Stability of VIII $_{\text {AHF }}$ activity in normal plasma. (A) Plasma from each of 16 normal subjects was diluted 1:10 in imidazole-saline buffer of varying $\mathrm{pH}$ values and incubated at $37^{\circ} \mathrm{C}$ for $4 \mathrm{~h}$. Circles depict the residual $\mathrm{VIII}_{\mathrm{AHF}}$ activity (mean value) for each $\mathrm{pH}$ value, as a percent of initial activity. (B) Plasmas from 11 normal subjects were diluted 1:10 in imidazolesaline, $\mathrm{pH} 7.1$, and incubated at $37^{\circ} \mathrm{C}$ for $1,2,4$, and $6 \mathrm{~h}$. For each incubation time, the residual VIII $_{\mathrm{AHF}}$ activity was determined. Dashed line connects mean values; solid lines connect mean \pm 2 SD values.

virtually identical to those obtained on the fresh specimens before freezing.) Incubation of these plasmas (diluted with 1:10 in imidazole-saline, $\mathrm{pH} 7.1$ ) for $6 \mathrm{~h}$ (Fig. 3 A) showed that VIII $_{\mathrm{AHF}}$ activity in the 48 -h (von Willebrand factor-poor) plasma was strikingly labile, whereas the activity in the 1-h (von Willebrand factor-rich) plasma was similar to that of normal plasma. The results were entirely similar with the plasmas obtained after transfusion study II. In this study, a progressive dissociation of the values of the factor VIII complex also occurred (Table I); for example, $78 \mathrm{~h}$ after the transfusion, the $\mathrm{VIII}_{\mathrm{AHF}}$ level was $95 \mathrm{U} / 100 \mathrm{ml}$, while that of VIII $\mathrm{VWF}_{\mathrm{VF}}$ and $\mathrm{VIII} \mathrm{IHF}_{\mathrm{AHF}}$ was 36 and $28 \mathrm{U} / 100$ $\mathrm{ml}$, respectively. As in study $\mathrm{I}$, the $\mathrm{VIII}_{\mathrm{AHF}}$ activity was more labile in the late (e.g., 30,54 , and $78 \mathrm{~h}$ ) posttransfusion plasmas that were (relative to $\operatorname{VIII}_{\mathrm{AHF}}$ ) von Willebrand-poor than the 5-h plasma (Fig. $3 \mathrm{~B}$ ). In the latter plasma, the stability of $\mathrm{VIII}_{\mathrm{AHF}}$ activity was normal.

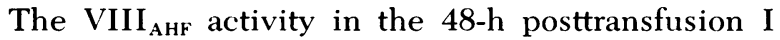
plasma could be stabilized by the prior addition of purified von Willebrand factor (Fig. $4 \mathrm{~A}$ ), which increased the VIII ${ }^{\mathrm{WWF}}$ and $\mathrm{VIII}_{\mathrm{AGN}}$ levels to 51 and 69 $\mathrm{U} / 100 \mathrm{ml}$, without any detectable effect on the $\mathrm{VIII}_{\mathrm{AHF}}$ level (Table I and Fig. $4 \mathrm{~A}$ ). Plasmas from hemophilic patients (which contain the von Willebrand factor; Table IV) also stabilized VIII $_{\text {AHF }}$ activity in the 48-h posttransfusion I plasma, whereas plasmas from three patients with severe von Willebrand's disease (Table IV) were without effect (Fig. 4 B).

The above studies indicate that the activity of VIII $_{\mathrm{AHF}}$ in posttransfusion plasmas that are relatively deficient in $\mathrm{VIII}_{\mathrm{VWF}}$ and/or $\mathrm{VIII}_{\mathrm{AGN}}$ is labile and can be stabilized either by purified von Willebrand factor or by plasmas that contain VIII $_{\mathrm{VWF}}$ activity, but not by plasmas deficient in this activity. The increased lability at $\mathrm{pH} 7.1$ of $\mathrm{VIII}_{\mathrm{AHF}}$ posttransfusion plasmas is not the result of a change in the optimum $\mathrm{pH}$ for maintaining VIII $_{\text {AHF }}$ activity, as demonstrated by the pH-stability curves shown in Fig. 5.

Aberrant nature of factor VIII in posttransfusion plasmas. The results of transfusion III (Table II) 
showed that, in addition to being more labile, the VIII $_{\mathrm{AHF}}$ activity in late posttransfusion plasma also eluted differently from Bio-Gel A-15m than that in normal or early posttransfusion plasma. As seen in Table II and Fig. 6, 84 $\pm 3 \%$ (SD) of the recovered VIII $_{\text {AHF }}$ activity from normal plasma eluted in the void volume. In plasma obtained 30,72 , and $96 \mathrm{~h}$ after transfusion, the void volume $\mathrm{VIII}_{\mathrm{AHF}}$ was 72,62 , and $53 \%$, respectively, of its total recovered activity. Note, however, that although a greater percentage of the VIII $_{\mathrm{AHF}}$ activity in the late posttransfusion samples eluted after the void volume, no sharp peak of lower molecular weight activity was observed. In addition, when these post-void volume fractions were pooled, concentrated in cellophane membranes (Spectrapor, Fisher Scientific Co., Pittsburgh, Pa.) against polyethylene glycol flakes (mol wt 20,000), and chromatographed on Bio-Gel A-15m in the presence of $0.002 \mathrm{M}$ $\mathrm{CaCl}_{2}$, which prevents re-aggregation of low molecular weight factor VIII (31), the VIII $_{\mathrm{AHF}}$ activity continued to elute after the void volume, but again, no sharp peak was observed. Measurements of the mobility of factor VIII antigen in 3-, 24-, and 48-h posttransfusion plasmas showed a progressive increase in mobility (Table II and Fig. 7). Mobilities in the 72-, 79-, and 96-h specimens would have required concentration of the plasmas, which was precluded by the limited volume of the samples available.

Increased lability of VIII ${ }_{A H F}$ activity in patients with von Willebrand's disease who have "aberrant" von Willebrand factor. The stability of plasma VIII $_{\text {AHF }}$ activity at $\mathrm{pH} 7.1$ was studied in seven patients (Table III) with "mild" von Willebrand's disease. Results are shown in Fig. 8. In four patients, stability of VIII $_{\mathrm{AHF}}$ was either normal or only slightly decreased (Fig. 8, open circles). In these four patients, the average ratio of $\mathrm{VIII}_{\mathrm{AHF}}$ activity to that of $\mathrm{VIII}_{\mathrm{VWF}}$ or VIII $_{\mathrm{AGN}}$ was 1.2 and 1.3 , respectively, and in no individual was this this ratio $>1.6$. The VIII $_{\mathrm{AHF}}$ activity was strikingly more labile in the plasma of the three other patients (Fig. 8, closed circles), in whom the ratios of VIII $_{\mathrm{AHF}}$ to $\mathrm{VIII}_{\mathrm{VWF}}$ and/or $\mathrm{VIII}_{\mathrm{AGN}}$ were greater, averaging 4.7 and 8.1, respectively. In two of these patients (J.L. and A.S., the third patient, J.M., was not studied), the elution pattern of $\mathrm{VIII}_{\mathrm{AHF}}$ after chromatography of plasma on Bio-Gel A-15m was different than

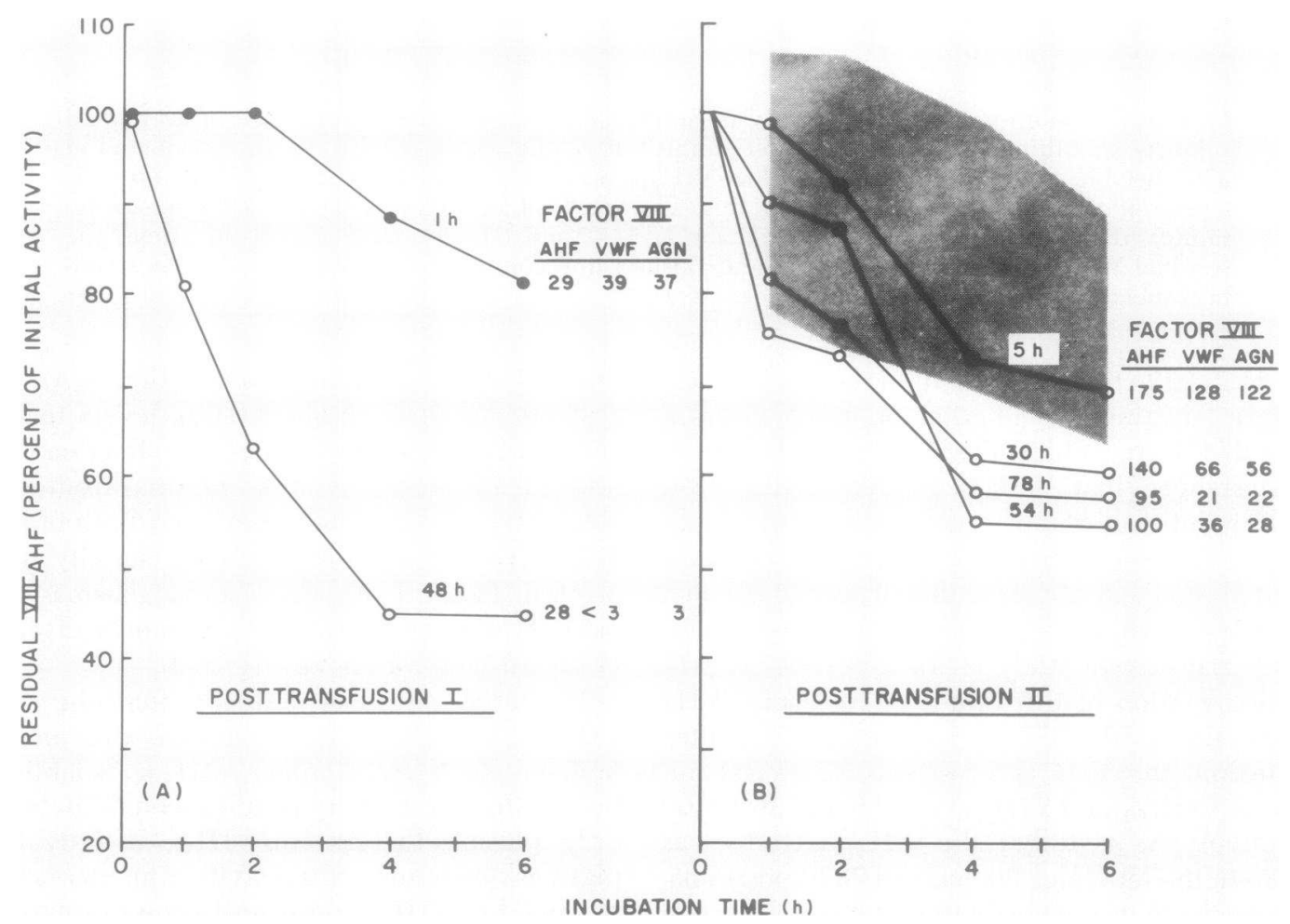

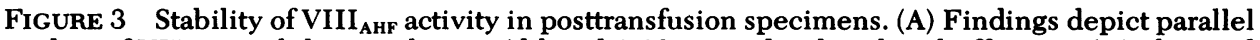
studies of VIII ${ }_{\mathrm{AHF}}$ stability in plasmas (diluted 1:10 in imidazole-saline buffer, pH 7.1) obtained $1 \mathrm{~h}$ and $48 \mathrm{~h}$ after administering cryoprecipitate to a patient with severe von Willebrand's disease (transfusion study I, Table I). The values of the factor VIII complex in these two plasmas before incubation are shown. (B) Same type of studies done on plasma obtained after transfusion II (see Table I). Shaded area encloses mean \pm 2 SD values of normal subjects (see Fig. 2 B). 


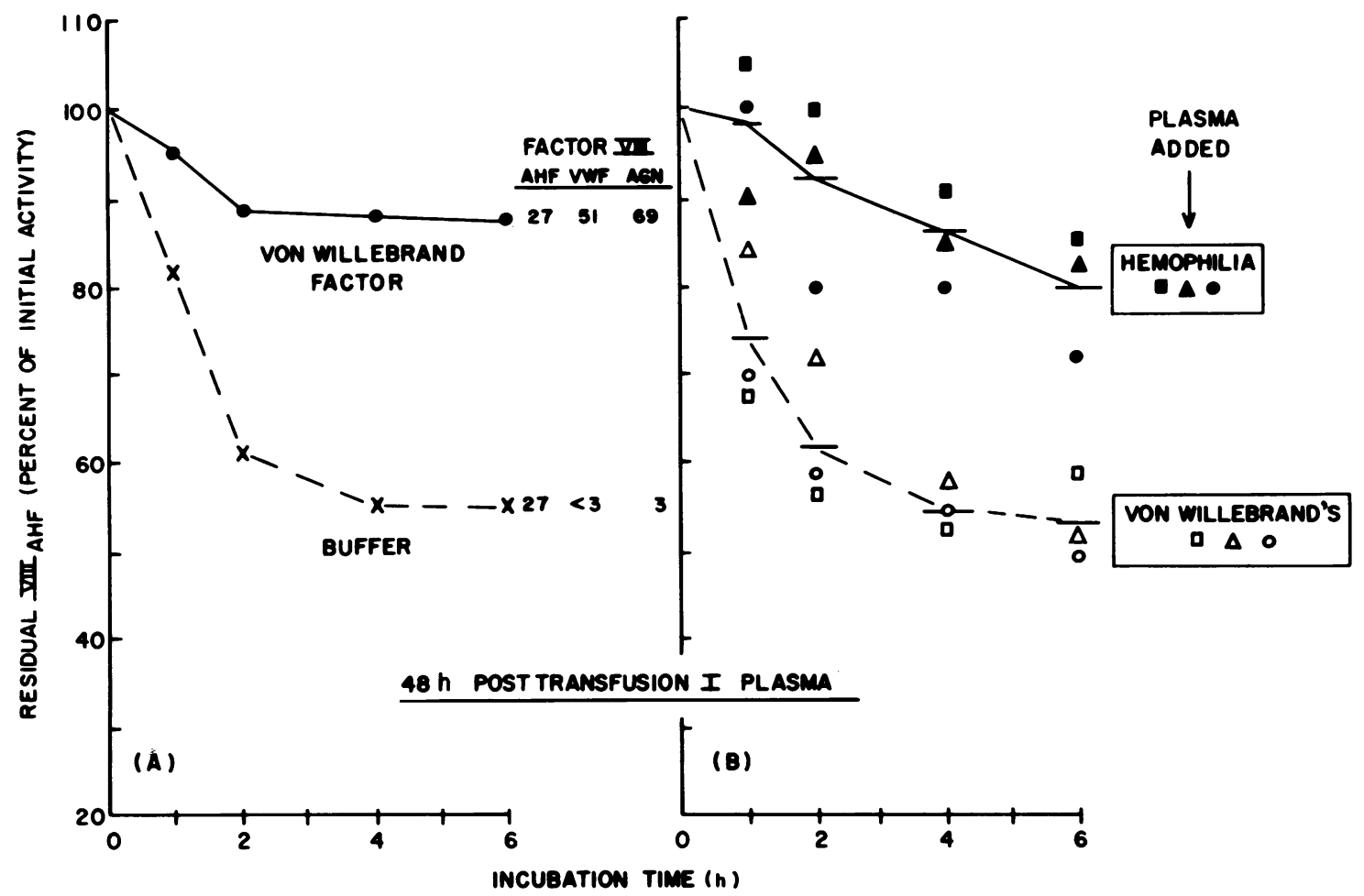

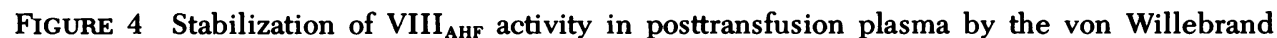
factor. (A) Purified von Willebrand factor or buffer was added (1/10 vol) to the 48-h posttransfusion plasma of study I (Table I). Values of the factor VIII complex on these specimens before incubation are shown and demonstrate the increase in the level of $\mathrm{VIII}_{\mathrm{VwF}}$ from $<3$ to $51 \mathrm{U} / 100$ ml. (B) The 48-h posttransfusion plasma $(0.2 \mathrm{ml})$ was mixed with $0.2 \mathrm{ml}$ of plasma from patients with hemophilia or severe von Willebrand's disease (Table IV) and then diluted with $3.6 \mathrm{ml}$ of imidazole-saline, $\mathrm{pH}$ 7.1. Lines connect the mean values (shown by bars) for each group of patients.

that obtained with normal plasma or other patients with von Willebrand's disease. In these two patients, a lesser percentage of the recovered $\mathrm{VIII}_{\mathrm{AHF}}$ activity was found in the void volume fractions (Table III). The remaining activity entered the gel, but, as was the case with the late posttransfusion plasmas, no distinct peak of low molecular weight activity was observed. In addition, the mobility of factor VIII antigen (studied by crossed immunoelectrophoresis) in these two patients was also more anodal than in normal subjects, or in other patients with von Willebrand's disease (Table III and Fig. 7). The above findings suggest that the von Willebrand factor/factor VIII-related protein may differ from normal in these patients with labile VIII $_{\mathrm{AHF}}$ activity.

Stabilization of VIII ${ }_{A H F}$ activity in "aberrant" von Willebrand's disease by the von Willebrand factor. As was true of the late posttransfusion plasmas of patient V.M., the VIII ${ }_{\mathrm{AHF}}$ activity in the plasma of patient A.S. could be stabilized by the addition of purified von Willebrand factor (Fig. $9 \mathrm{~A}$ ) and by plasmas of patients with hemophilia (Fig. 9 B). In contrast, plas- mas of patients with severe von Willebrand's disease were without effect (Fig. 9 B). Entirely similar results were obtained with plasmas of the other two patients (J.L. and J.M.) with aberrant von Willebrand factor (Fig. 10). In separate studies in which normal plasma was mixed with equal volumes of either buffer, hemophilic plasma, or plasma of a patient with severe von Willebrand's disease, we found that von Willebrand plasma did not "destabilize" the $\mathrm{VIII}_{\mathrm{AHF}}$ activity of normal plasma (data not shown).

Stability of VIII $_{A H F}$ activity in dissociated, low molecular weight factor VIII. Low molecular weight factor VIII, containing VIII ${ }_{\mathrm{AHF}}$ activity, but no detectable VIII $_{\mathrm{VWF}}$ activity, was incubated with plasmas of patients with hemophilia or von Willebrand's disease. Results are shown in Fig. 11. The VIII AHF $_{\text {f }}$ activity appeared to be more stable than that in native, normal plasma; therefore, longer incubation periods $(24-48 \mathrm{~h})$ were required to demonstrate significant loss of activity. Nevertheless, even with these modified conditions of incubation, the VIII $\mathrm{AHF}_{\mathrm{Ar}}$ activity of "low molecular weight factor VIII" was considerably more 
stable in hemophilic plasma than in the plasma of patients with von Willebrand's disease (Fig. 11).

Cryoprecipitability of VIII $_{A H F}$ activity. As shown in Table II, the ratio of $\mathrm{VIII}_{\mathrm{AHF}}$ in the cryoprecipitate to that in the supernate $(\mathrm{C} / \mathrm{S})$ was $3.7 \pm 1.3(\mathrm{SD})$ in normal subjects. In four patients with von Willebrand's disease, the $\mathrm{C} / \mathrm{S}$ ratio was within the mean $\pm 2 \mathrm{SD}$ values of normal subjects. The cryoprecipitability of VIII $_{\mathrm{AHF}}$ was low in the three patients with "labile" VIII $_{\mathrm{AHF}}$ and low VIII $\mathrm{VWF}_{\mathrm{F}} / \mathrm{VIII}_{\mathrm{AGN}}$ values. In patient J. L., cryoprecipitability was only moderately reduced $(\mathrm{C} / \mathrm{S}=1.0)$, whereas strikingly low values $(0.3$ and 0.1$)$ were obtained in patients $J$. M. and A. S. When the plasma of patient A. S. was mixed with equal parts of hemophilic plasmas before freezing, the $\mathrm{C} / \mathrm{S}$ ratio increased to 0.5 (mean of three different plasmas), whereas it remained 0.1 when mixed with plasmas of patients with von Willebrand's disease. Decreased cryoprecipitability was also found in the late posttransfusion plasmas (patient V. M.) that were relatively deficient in VIII ${ }_{\mathrm{VWF}}$ activity (Table I). Addition of von Willebrand factor to the 48 -h posttransfusion plasmas of study I increased the cryoprecipitability of $\mathrm{VIII}_{\mathrm{AHF}}$ from 0.4 to 1.1 .

Attempts to stabilize VIII ${ }_{A H F}$ activity in normal plasma. The addition of the following substances to normal plasma did not stabilize the VIII ${ }_{\mathrm{AHF}}$ activity during $6 \mathrm{~h}$ of incubation: heparin $(0.025$ and $0.05 \mathrm{U} / \mathrm{ml})$, Trasylol $(100 \mathrm{U} / \mathrm{ml}), \epsilon$-amino caproic acid $0.05 \mathrm{M}$, STI $\left(10^{-4} \mathrm{M}\right)$, or benzamidine $\mathrm{HCl}\left(10^{-4} \mathrm{M}\right)$. The presence of sodium azide in the diluting buffer did not increase the stability of VIII $_{\mathrm{AHF}}$ in either normal plasma, the plasma of patient A. S., or late posttransfusion plasmas showing increased VIII $_{\mathrm{AHF}}$ lability.

\section{DISCUSSION}

The structure-function relationships of factor VIII that determine the plasma levels of $\mathrm{VIII}_{\mathrm{AHF}}, \mathrm{VIII}_{\mathrm{VWF}}$, and VIII $_{\mathrm{AGN}}$ are not clear. It is generally agreed that $\mathrm{VIII}_{\mathrm{AGN}}$ is a property of a $1.2 \times 10^{6}$ dalton molecule that is composed of 200,000 mol wt subunits and possesses VIII $_{\mathrm{VWF}}$ activity as well $(2,32)$. Thus, impaired association of abnormally charged subunits $(9,10,33,34)$

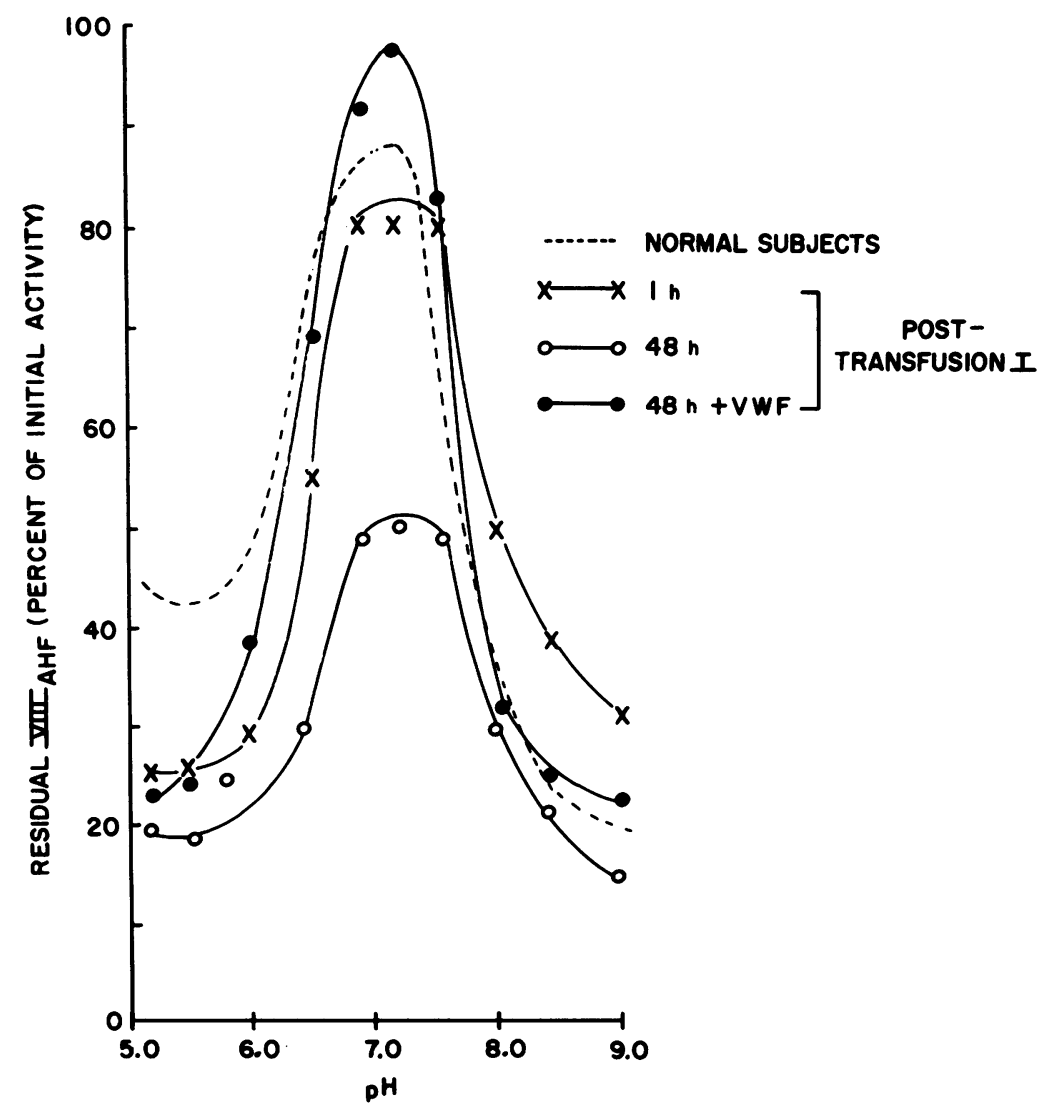

FIGURE $5 \mathrm{pH}$-Stability curves on posttransfusion plasmas. Plasmas (study I, Table I) were diluted 1:10 with imidazole-saline ( $\mathrm{pH}$ 7.1) of varying $\mathrm{pH}$ values and incubated at $37^{\circ} \mathrm{C}$ for $4 \mathrm{~h}$. Depicted are the curves obtained for the 1-h plasma $(\times)$, the 48-h plasma $(O)$, and the 48-h plasma to which purified von Willebrand factor had been added $(0)$. The curve obtained with normal plasmas (Fig. $2 \mathrm{~A}$ ) is shown by the dashed line (-- $)$. 


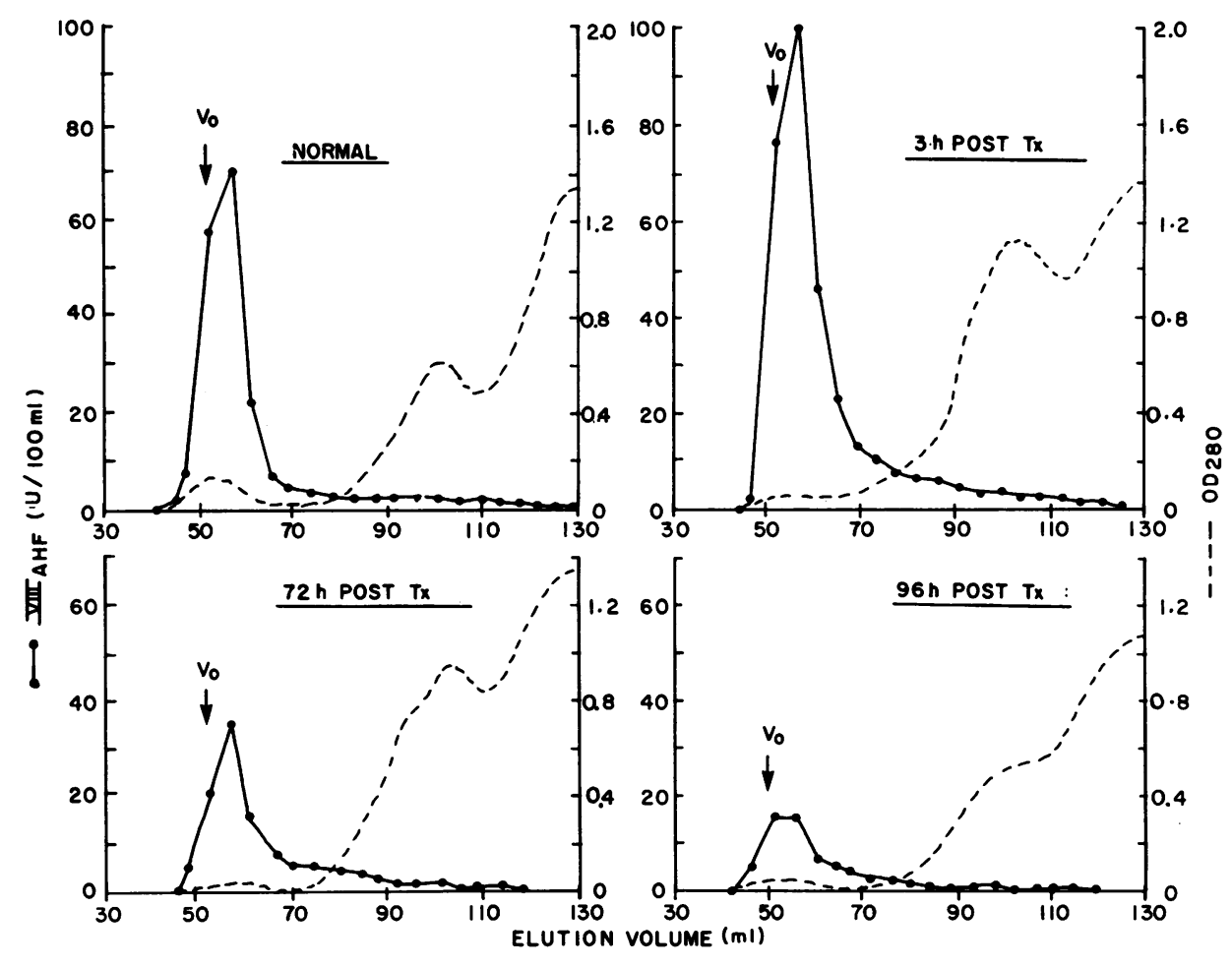

FIGURE 6 Chromatography of normal and posttransfusion plasmas on Bio-Gel A-15m. $8 \mathrm{ml}$ of plasma was chromatographed on Bio-Gel A-15m $(2.6 \times 28.5 \mathrm{~cm})$. In normal plasma, $84 \pm 3 \%$ (SD) of the recovered VIII ${ }_{\mathrm{AHF}}$ is eluted as a sharp peak in the void volume (see Table II). In the late $\left(72\right.$ and $96 \mathrm{~h}$ ) posttransfusion ( $\mathrm{T}_{\mathrm{x}}$ ) III plasmas of patient $\mathrm{V}$. M., a relatively lesser percent of the recovered activity was found in the void volume (see also Table II), but there was no sharp peak of activity eluting after the void volume.

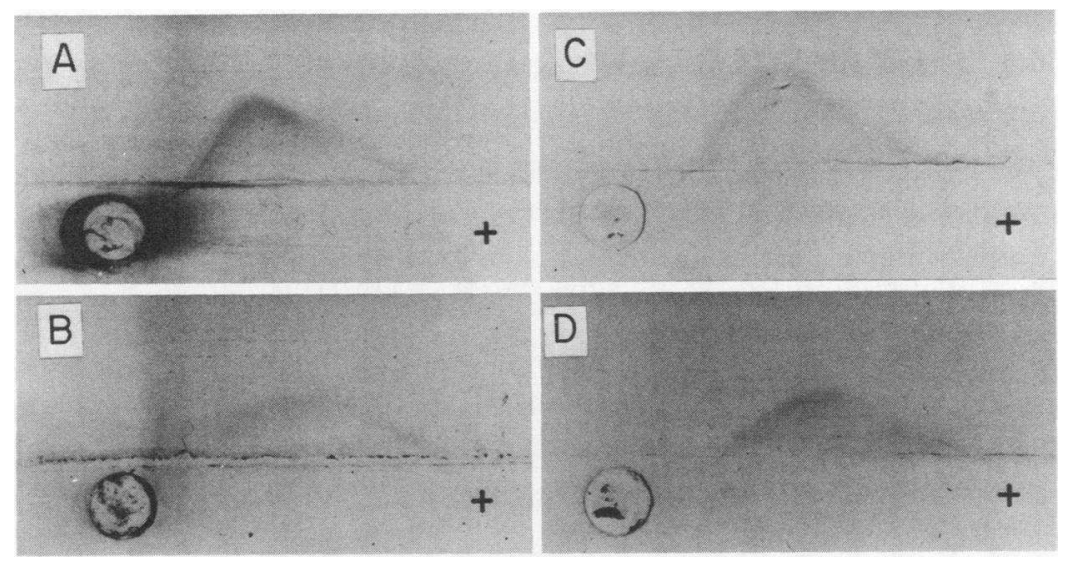

FIGURE 7 Crossed immunoelectrophoresis pattern of factor VIII-related antigen. (A) Normal plasma. The anode in the first electrophoretic separation is to the right; that for the second separation is at the top of the figure. (B) Concentrated plasma from patient A. S. Although the peak height is less, the major fraction of this protein has a faster mobility than the peak value for normal plasma. This separation is typical of four such electrophoretic separations. (C) Plasma obtained from patient V. M. $3 \mathrm{~h}$ after the last transfusion of cryoprecipitate (transfusion III). (D) $48 \mathrm{~h}$ posttransfusion III. Most of the factor VIII protein has a faster mobility than that obtained $3 \mathrm{~h}$ after transfusion. 


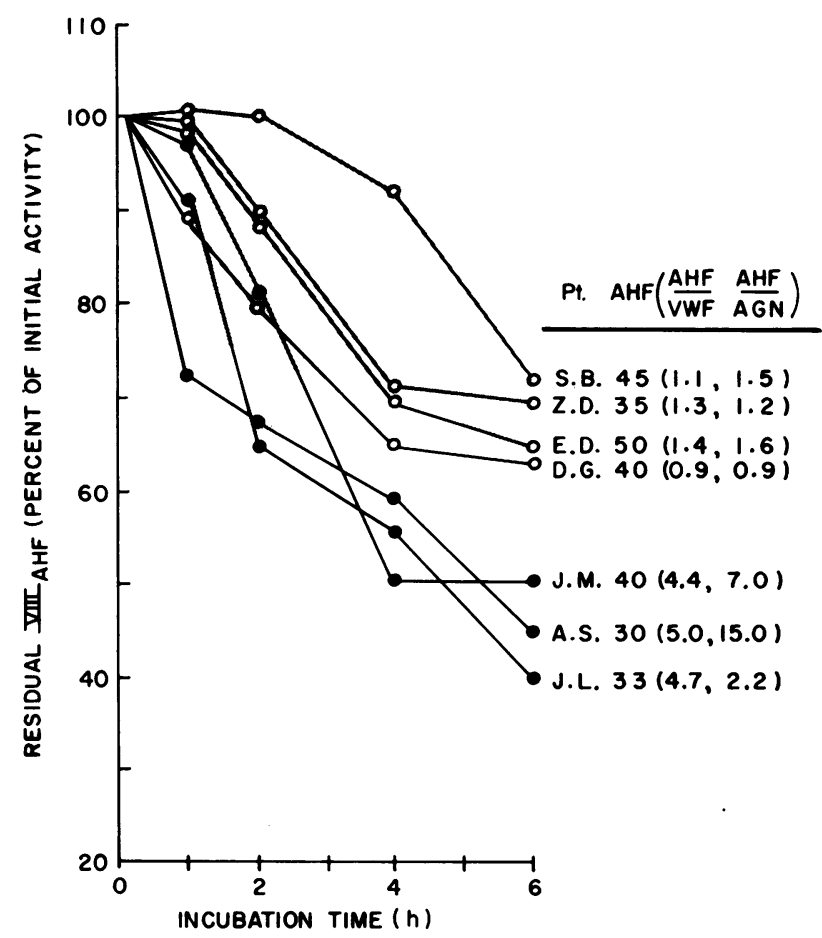

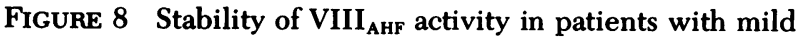
von Willebrand disease. Plasmas of the seven patients shown in Table II were diluted $1: 10$ with imidazole-saline ( $\mathrm{pH} 7.1$ ) and incubated at $37^{\circ} \mathrm{C}$ for $1,2,4$, and $6 \mathrm{~h}$. Shaded area encloses mean \pm 2 SD values of normal subjects (see Fig. $2 \mathrm{~B}$ ). VIII $\mathrm{AHF}_{\mathrm{A}}$ activity was most labile in the three patients $(O)$ in whom the ratios of $\mathrm{VIII}_{\mathrm{AHF}}$ to $\mathrm{VIII}_{\mathrm{VWF}}$ and $\mathrm{VIII}_{\mathrm{AHF}}$ to $\mathrm{VIII}_{\mathrm{AGN}}$ (calculated from data in Table II) were increased. In two patients (A. S. and J. L.) the mobility of VIII $_{\mathrm{AGN}}$ was increased as well (Table II).

might account for the decreased $\mathrm{VIII}_{\mathrm{VWF}}$ activity (relative to that of $\mathrm{VIII}_{\mathrm{AHF}}$ ) that has been observed in some patients with von Willebrand's disease and in patients J. L. and A. S. (Table III) reported herein. In addition, there is evidence that the protein carry-

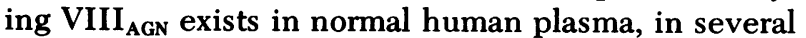
different sizes (possibly with different charges as well), presumably as a consequence of the association of different numbers of subunits (35). The possibility that the molecular weight of the intact molecule carrying VIII $_{\mathrm{AGN}}$ and VIII $_{\mathrm{VWF}}$ may be considerably less than $1.2 \times 10^{6}$ daltons has also been suggested (36).

The molecular relationship of VIII $_{\mathrm{AHF}}$ to $\mathrm{VIII}_{\mathrm{VWF}}$ VIII $_{\text {AGN }}$ has not been entirely resolved and remains the subject of considerable controversy. One theory proposes that $\mathrm{VIII}_{\mathrm{AHF}}$ is a function of a single protein (factor VIII) that has two distinct biologic properties (24-26). Proponents of this theory suggest that the apparent dissociation of factor VIII by buffers of high ionic strength is the result of selective adsorption on agarose of the relatively small number of factor VIII molecules on which VIII $_{\mathrm{AHF}}$ is active (24-26). However, dissociation of factor VIII into smaller subunits with VIII $_{\mathrm{AHF}}$ activity has also been achieved with sucrose density ultracentrifugation $(37,38)$, a method in which adsorption cannot play a role. A second theory holds that VIII $_{\mathrm{AHF}}$ activity is the property of a molecule that is distinct from that responsible for $\mathrm{VIII}_{\mathrm{VWF}}$ but whose plasma level is somehow determined by it $(39,40)$, or is noncovalently bound to $\mathrm{VIII}_{\mathrm{VWF}}$ (carrier hypothesis) $(41,42)$. The evidence supporting both the one- and two-molecule theories has been summarized recently $(2,43)$, and it is clear that the problem will not be solved until "low molecular weight" $\mathrm{VIII}_{\mathrm{AHF}}$ - free of the protein carrying $\mathrm{VIII}_{\mathrm{AGN}} / \mathrm{VIII}_{\mathrm{VWF}}$-is obtained in sufficient quantity for analysis so that its structure can be compared with that of $\mathrm{VIII}_{\mathrm{VWF}}$ / VIII $_{\text {AGN }}(2)$.

The uncertainties about the molecular structure of the factor VIII complex make it difficult to know the basis for dissociation of VIII $_{\mathrm{AHF}}$ from $\mathrm{VIII}_{\mathrm{VWF}} / \mathrm{VIII}_{\mathrm{AGN}}$ observed in the plasmas of some patients with von Willebrand's disease, as well as in the posttransfusion plasmas of other patients. Earlier studies by Barrow et al. (44) suggested that posttransfusion $\mathrm{VIII}_{\mathrm{AHF}}$ was indistinguishable from normal $\mathrm{VIII}_{\mathrm{AHF}}$, as judged by its inactivation at $50^{\circ} \mathrm{C}$ and $\mathrm{pH}$-dependent stability. Subsequently, however, other investigators have reported that the VIII $_{\mathrm{AHF}}$ activity in posttransfusion plasmas of both humans $(6,45)$ and pigs $(46)$ with von Willebrand's disease appears to lose its activity more rapidly than that in normal plasmas when stored at $-20^{\circ} \mathrm{C}$. The results obtained in the present study confirm and extend these latter findings by demonstrating that the VIII $_{\mathrm{AHF}}$ is relatively more labile in late posttransfusion plasmas, in which VIII $_{\mathrm{AHF}}>\mathrm{VIII}_{\mathrm{VWF}}$ activity, but that the stability of $\mathrm{VIII}_{\mathrm{AHF}}$ in early posttransfusion plasma $\left(\mathrm{VIII}_{\mathrm{AHF}} \sim \mathrm{VIII}_{\mathrm{VWF}}\right)$ is the same as in normal plasma. Furthermore, VIII $_{\mathrm{AHF}}$ in late posttransfusion plasmas show diminished cryoprecipitability. Both the increased lability of VIII $\mathrm{AHF}_{\mathrm{An}}$ and the decreased cryoprecipitability appear to be related to the increased VIII $_{\mathrm{AHF}}$ to VIII $_{\mathrm{VWF}}$ ratio in late posttransfusion plasmas; both abnormalities can be corrected by the addition of a purified plasma fraction that contains VIII $_{\mathrm{VWF}}$ but is lacking in VIII $\mathrm{AHF}_{\mathrm{Ac}}$ activity. Plasmas from hemophilic patients (which contain VIII $_{\mathrm{VWF}}$ ) also stabilized VIII $_{\mathrm{AHF}}$ activity, whereas those from patients with severe von Willebrand's disease did not. Thus, VIII ${ }_{\mathrm{VWF}}$ appears to stabilize VIII $_{\mathrm{AHF}}$ specifically.

It is of interest to consider the possible relationship of these findings to the "over-response" of VIII ${ }_{\mathrm{AHF}}$ observed after transfusion in von Willebrand's disease. An important missing piece of information, however, is whether the increased lability of VIII $_{\mathrm{AHF}}$ in vitro is equally true in vivo. We have no evidence on this point. Previous studies suggested that the loss of 


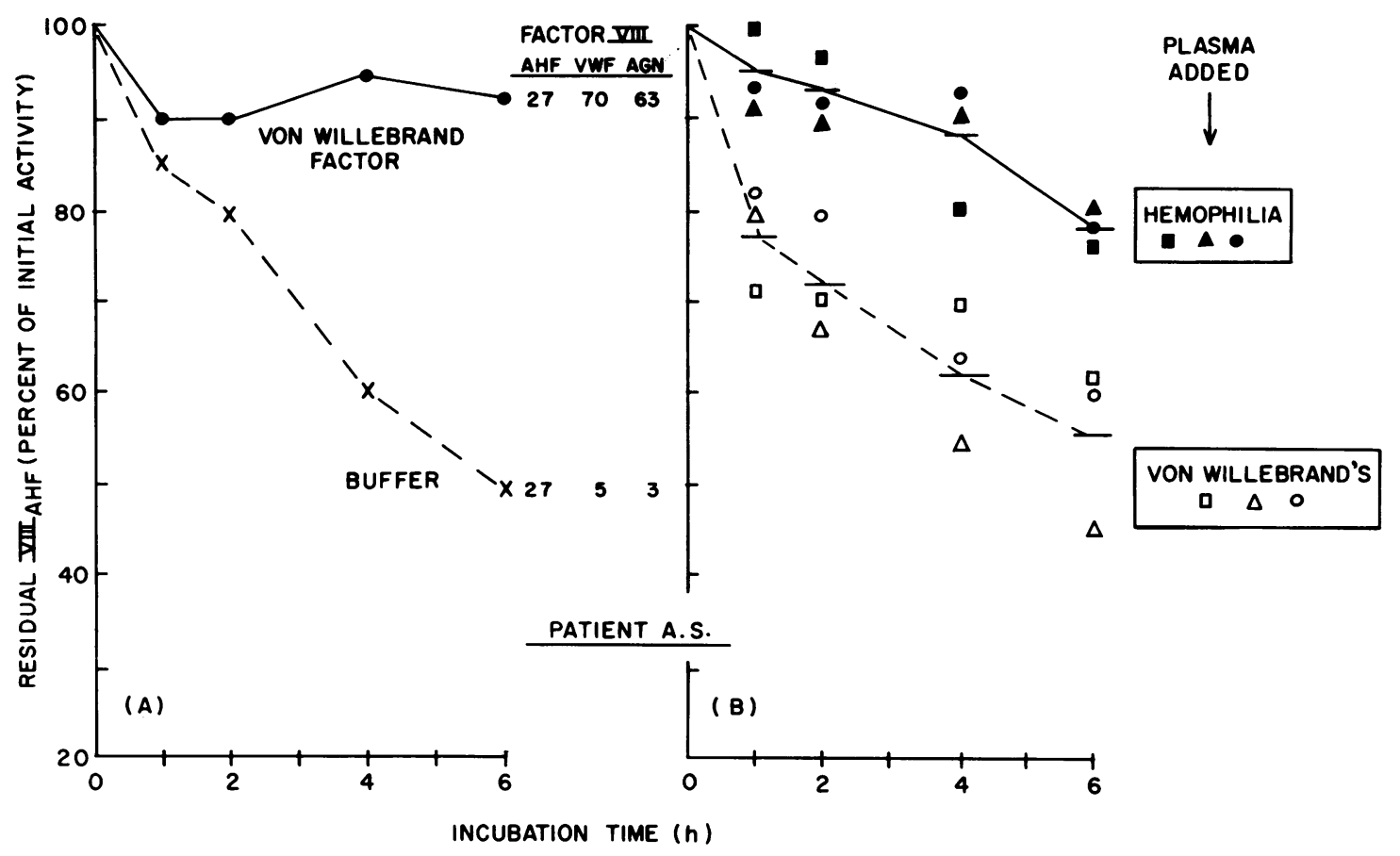

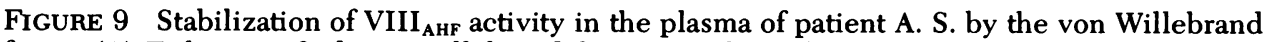
factor. (A) Either purified von Willebrand factor or column buffer was added (1/10 vol) to the

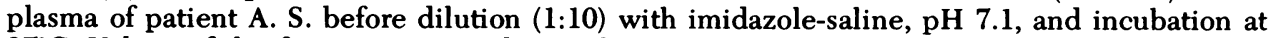
$37^{\circ} \mathrm{C}$. Values of the factor VIII complex in these specimens before incubation are shown and demonstrate an increase in the level of $\mathrm{VIII}_{\mathrm{VWF}}$ from 5 to $70 \mathrm{U} / 100 \mathrm{ml}$. (B) $0.2 \mathrm{ml}$ of A. S. plasma were mixed with $0.2 \mathrm{ml}$ of plasma from patients with either hemophilia (closed figures) or von Willebrand's disease (open figures; see Table III). The mixtures were diluted with $3.6 \mathrm{ml}$ of imidazole-saline, $\mathrm{pH} 7.1$, and incubated at $37^{\circ} \mathrm{C}$. Lines connect mean values (bars) for each of the two groups shown.

activity of $\mathrm{VIII}_{\mathrm{AHF}}$ in normal plasma during incubation at $37^{\circ} \mathrm{C}$ is enzymatic in nature $(29,47)$. In neither of these studies, nor in the present study, was an enzymatic process identified, although it is of some interest that Kekwick and Walton (48) have described the presence of a diisopropylfluorophosphate-sensitive inhibitor of $\mathrm{VIII}_{\mathrm{AHF}}$ in factor VIII concentrates. If the in vitro findings in the present study are true in vivo, it is possible that the von Willebrand factor may serve to stabilize VIII $_{\mathrm{AHF}}$ in vivo (and possibly promote its release from its site of synthesis), thereby increasing the levels of VIII $_{\mathrm{AHF}}$ activity in plasma. The basis for the posttransfusion response in von Willebrand's disease would thus represent the presence in plasma of $\mathrm{VIII}_{\mathrm{AHF}}$, synthesized under the control of normal $\mathrm{X}$ chromosomes, which is stabilized by the presence of added "normal" $\mathrm{VIII}_{\mathrm{AGN}} / \mathrm{VIII}_{\mathrm{VWF}}$ protein. The different ratios of VIII $_{A H F}$ to VIII $_{\mathrm{VWF}} / \mathrm{VIII}_{\mathrm{AGN}}$ - compared to the normal plasma standard-in these situations cannot be interpreted on a molecular basis at this time because the exact molecular weights, concentrations, and combining ratios of these properties are not known absolutely but are only compared to those of a reference plasma.
At our present level of understanding, the stabilizing effect of VIII $_{\mathrm{VWF}}$ on VIII $_{\mathrm{AHF}}$ activity does not provide new information that allows choices between a onemolecule or two-molecule theory for factor VIII. For example, the $\mathrm{VIII}_{\mathrm{VWF}}$ might inhibit the activity of a plasma protease that inactivates VIII $_{\mathrm{AHF}}$ (two separate molecule theory). Alternatively, it might, as a carrier, bind VIII $_{\mathrm{AHF}}$ and thereby prevent its inactivation. This theory has been proposed by Bloom et al. (41) who reported that some of the posttransfusion VIII $_{\text {AHF }}$ eluted from agarose gels in a sharp peak after the void volume, suggesting that this represented unbound VIII $_{\mathrm{AHF}}$. This finding was not confirmed in our experiments nor in those of Muntz et al. (6). Although we did find that a relatively greater percent of the recovered VIII $_{\mathrm{AHF}}$ eluted after the void volume (Table II), no sharp peak was discernible (Fig. 6). An alternative explanation, based on the one-molecule hypothesis, might be that factor VIII, with active procoagulant activity $\left(\mathrm{VIII}_{\mathrm{AHF}}\right)$, is specifically synthesized and released after transfusion, but that this is relatively labile in vitro and can be converted to an inactive form. Thus, addition of the von Willebrand factor (either purified from normal plasma or present in 

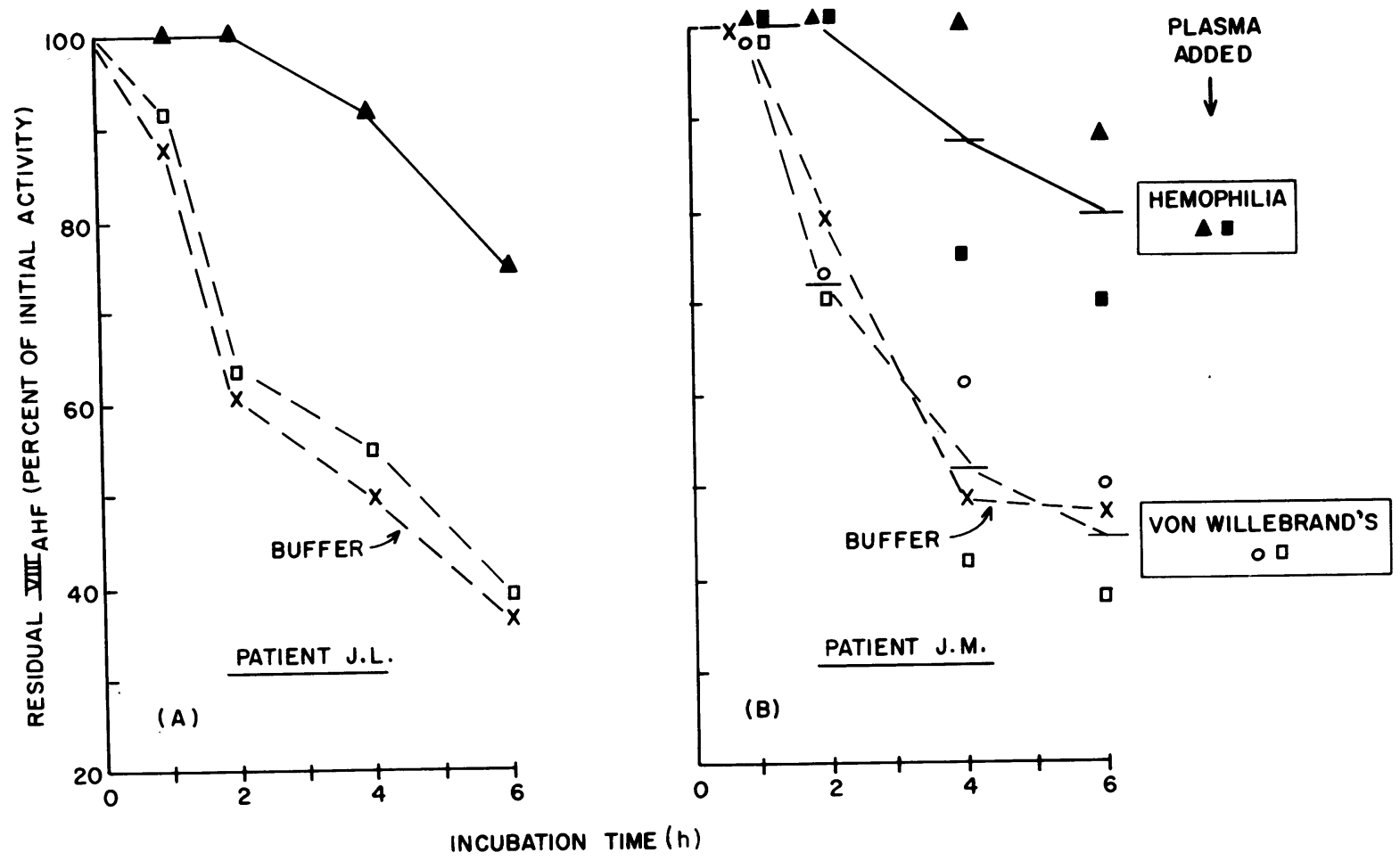

(B)

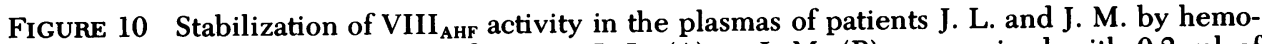
philic plasma. $0.2 \mathrm{ml}$ of plasma of patient J. L. (A) or J. M. (B) were mixed with $0.2 \mathrm{ml}$ of plasma from patients with either hemophilia (closed figures) or von Willebrand's disease (open figures; see Table III), or with buffer $(x---x)$. The mixtures were diluted with $3.6 \mathrm{ml}$ of imidazole-saline, $\mathrm{pH} 7.1$, and incubated at $37^{\circ} \mathrm{C}$. For patient J. M., lines connect mean values (bars).

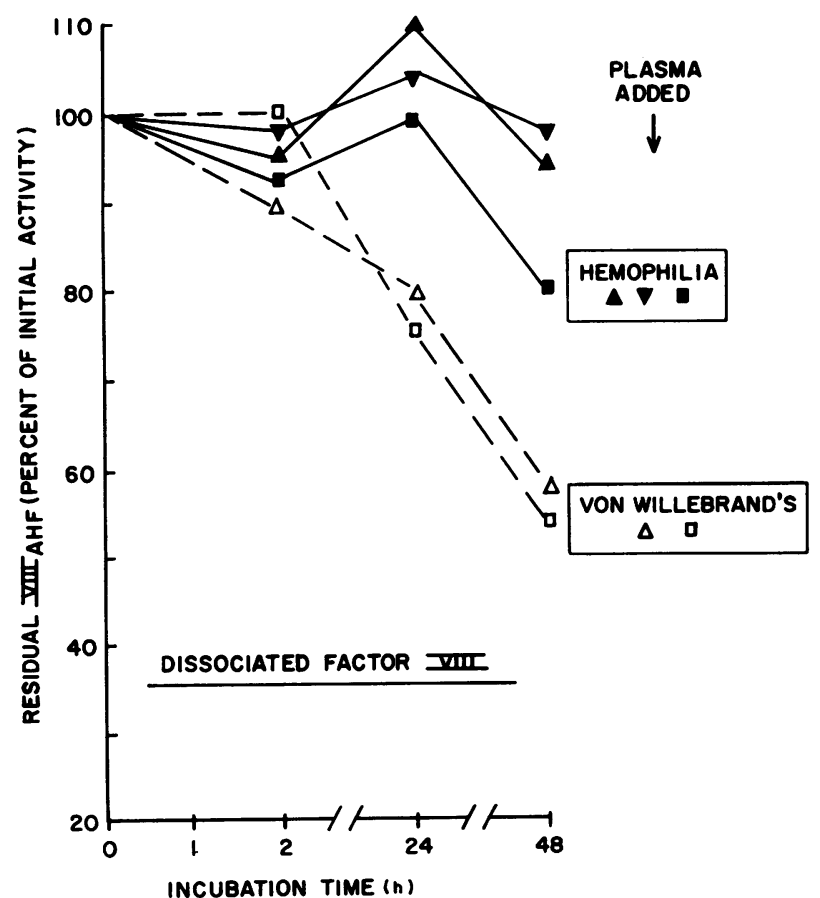

hemophilic plasma) would shift the reaction in a way that would maintain an active species.

The findings obtained in posttransfusion plasmas are similar to those in the three patients with von Willebrand's disease who showed the dissociation phenomena, i.e., VIII $_{\mathrm{AHF}}$ values $>\mathrm{VIII}_{\mathrm{VWF}}$. $\mathrm{VIII}_{\mathrm{AHF}}$ in these plasmas was also labile, whereas this was not the case in four other patients in whom VIII $_{\mathrm{AHF}}$ levels were similar to those for VIII $\mathrm{VWF}_{\mathrm{VW}}$. As in the late posttransfusion plasmas, the increased lability of $\mathrm{VIII}_{\mathrm{AHF}}$ in the plasmas of these patients could also be corrected by von Willebrand factor or hemophilic plasmas that contained $\mathrm{VIII}_{\mathrm{VWF}}$, but not by plasmas of patients with von Willebrand's disease. Furthermore, the increased mobility of VIII AGN $_{\text {on crossed immunoelectro- }}$

FIGURE 11 VIII $_{\text {AHF }}$ stability of dissociated, low molecular weight factor VIII in hemophilic and von Willebrand plasma. $0.4 \mathrm{ml}$ of dissociated factor VIII (see Methods) was mixed with an equal volume of plasma from patients with hemophilia (closed figures) or with von Willebrand's disease (open figures; see Table III). The mixture was diluted with $3.2 \mathrm{ml}$ of $0.05 \mathrm{M}$ imidazole-saline, $\mathrm{pH} 7.2$, and incubated at $37^{\circ} \mathrm{C}$. Initial VIII $_{\mathrm{AHP}}$ activity was $12 \mathrm{U} / 100 \mathrm{ml}$. 
phoresis in two of these patients, as well as decreased cryoprecipitability of $\mathrm{VIII}_{\mathrm{AHF}}$, and the delayed elution pattern of $\mathrm{VIII}_{\mathrm{AHF}}$ after agarose gel chromatography, demonstrates properties of factor VIII in these patients that are similar to those of late posttransfusion plasma. These three observations may, in fact, represent consequences of a shift in factor VIII size in these situations. Zimmerman and his co-workers (35) have demonstrated that the faster-moving forms on crossed immunoelectrophoresis are probably due to reduced size, not increased charge, and this property is consistent with the slightly later elution patterns on agarose gel chromatography. The relationship of cryoprecipitability to large size has also been identified in these studies (35). Thus, our findings for these patients with von Willebrand variants and aberrant $\mathrm{VIII}_{\mathrm{VWF}}$ provide additional evidence that VIII $_{\mathrm{AHF}}$ is relatively labile in vitro in the absence of normal VIII ${ }_{\mathrm{VWF}}$. They emphasize that the abnormalities in VIII $_{\mathrm{VWF}}$ structure and concentration are central to the factor VIII defect in von Willebrand's disease.

\section{ACKNOWLEDGMENTS}

The authors wish to thank Mr. John Rogers for his expert technical assistance.

This work was supported in part by grants HL 14595, HL 16626, and HL 16872 from the National Heart, Lung, and Blood Institute.

\section{REFERENCES}

1. Weiss, H. J. 1975. Platelet physiology and abnormalities of platelet function. N. Engl. J. Med. 293: 531-541, 580-588.

2. Hoyer, L. W. 1976. Von Willebrand's disease. In Progress in Hemostasis and Thrombosis. Vol. 3 T. H. Spaet, editor. Grune \& Stratton, Inc., N. Y. 231-287.

3. Weiss, H. J., L. W. Hoyer, R. F. Rickles, A. Varma, and J. Rogers. 1973. Quantitative assay of a plasma factor deficient in von Willebrand's disease that is necessary for platelet aggregation: relationship to decreased factor VIII procoagulant activity and antigen content. J. Clin. Invest. 52: 2708-2716.

4. Meyer, D., C. S. P. Jenkins, M. D. Dreyfus, E. Fressinaud, and M-J. Larrieu. 1974. Willebrand factor and ristocetin. II. Relationship between Willebrand factor, Willebrand antigen and factor-VIII activity. Br. J. Haematol. 28: 579-599.

5. Bennett, B., O. D. Ratnoff, and J. Levin. 1972. Immunologic studies in von Willebrand's disease: evidence that the antihemophilic factor (AHF) produced after transfusions lacks an antigen associated with normal AHF and the inactive material produced by patients with classic hemophilia. J. Clin. Invest. 51: 2597-2601.

6. Muntz, R. H., H. Ekert, and H. Helliger. 1974. Properties of post-infusion factor VIII in von Willebrand's disease. Thromb. Res. 5: 111-123.

7. Rickles, F. R., L. W. Hoyer, M. E. Rick, and D. J. Ahr. 1976. The effects of epinephrine infusion in von Willebrand's disease. J. Clin. Invest. 57: 1618-1625.

8. Firkin, B., F. Firkin, and L. Scott. 1973. Von Willebrand's disease type B: a newly defined bleeding diathesis. Aust. N. Z. J. Med. 3: 225-229.
9. Peake, I. R., A. L. Bloom, and J. C. Giddings. 1974. Inherited variants of factor VIII-related proteins in von Willebrand's disease. N. Engl. J. Med. 291: 113-117.

10. Gralnick, H. R., B. S. Coller, and Y. Sultan. 1975. Studies of the human factor VIII/von Willebrand factor protein. III. Qualitative defects in von Willebrand's disease. J. Clin. Invest. 56: 814-827.

11. Holmberg, L., I. M. Nilsson, and N. Rasovic. 1974. Factor VIII in von Willebrand's disease. Lancet. 2: 1027.

12. Veltkamp, J. J., and N. H. van Tilburg. 1973. Detection of heterozygotes for recessive von Willebrand's disease by the assay of antihemophilic-factor-like antigen. N. Engl. J. Med. 289: 882-885.

13. Owen, W. G., and R. H. Wagner. 1972. Antihemophilic factor: separation of an active fragment following dissociation by salts on detergents. Thromb. Diath. Haemorrh. 27: $502-515$.

14. Weiss, H. J., L. L. Phillips, and W. Rosner. 1972. Separation of sub-units of antihemophilic factor (AHF) by agarose gel chromatography. Thromb. Diath. Haemorrh. 27: 212-219.

15. Weiss, H. J., and L. W. Hoyer. 1973. Von Willebrand factor: dissociation from antihemophilic factor procoagulant activity. Science (Wash. D. C.). 182: 1149-1151.

16. Austen, D. E. G. 1974. Factor VIII of small molecular weight and its aggregation. Br. J. Haematol. 27: 89-100.

17. Rick, M. E., and L. W. Hoyer. 1973. Immunologic studies of antihemophilic factor (AHF, factor VIII). V. Immunologic properties of AHF subunits produced by salt dissociation. Blood. 42: 737-747.

18. Sussman, I. I., W. Rosner, and H. J. Weiss. 1976. Concentration-dependent dissociation of factor VIII in $1 \mathrm{M}$ NaCl. Am. J. Physiol. 230: 434-440.

19. Hoyer, L. W. 1972. Immunologic studies of antihemophilic factor (AHF, factor VIII). VI. Radioimmunoassay of AHF antigen. J. Lab. Clin. Med. 80: 822-833.

20. Cooper, H. A., T. R. Griggs, and R. H. Wagner. 1973. Factor VIII recombination after dissociation by $\mathrm{CaCl}_{2}$. Proc. Natl. Acad. Sci. U. S. A. 70: 2326-2329.

21. Weber, K., and M. Osborn. 1969. The reliability of molecular weight determinations by dodecyl sulfatepolyacrylamide gel electrophoresis. J. Biol. Chem. 244: 4406-4412.

22. Legaz, M. E., G. Schmer, R. B. Counts, and E. W. Davie. 1973. Isolation and characterization of human factor VIII (antihemophilic factor). J. Biol. Chem. 248: 3946-3955.

23. Marchesi, S. L., N. R. Shulman, and H. R. Gralnick. 1972. Studies on the purification and characterization of human factor VIII. J. Clin. Invest. 51: 2151-2161.

24. McKee, P. A., J. C. Anderson, and M. E. Switzer. 1975. Molecular studies of human factor VIII. Ann. N. Y. Acad. Sci. 240: 8-33.

25. Shapiro, G. A., J. C. Anderson, S. V. Pizzo, and P. A. McKee. 1973. The subunit structure of normal and hemophilic factor VIII. J. Clin. Invest. 52: 2198-2210.

26. Switzer, M. E., and P. A. McKee. 1976. Studies on human antihemophilic factor: evidence for a covalently linked subunit structure. J. Clin. Invest. 57: 925-937.

27. Jaffe, E. A., and R. L. Nachman. 1975. Subunit structure of factor VIII antigen synthesized by cultured human endothelial cells. J. Clin. Invest. 56: 698-702.

28. Zimmerman, T. S., L. W. Hoyer, L. Dickson, and T. S. Edgington. 1975. Determination of the von Willebrand's disease antigen (factor VIII-related antigen) in plasma by quantitative immunoelectrophoresis. J. Lab. Clin. Med. 86: 152-159. 
29. Weiss, H. J. 1965. A study of the cation- and pHdependent stability of factors $\mathrm{V}$ and VIII in plasma. Thromb. Diath. Haemorrh. 14: 32-51.

30. Wolf, P. 1959. Studies of temperature and $\mathrm{pH}$ stability of human antihaemophilic factor (AHF) in plasma and in a concentrate. Br. J. Haematol. 5: 169-176.

31. Sussman, I. I., and H. J. Weiss. 1976. Spontaneous aggregation of low molecular weight factor VIII and its prevention by $2 \mathrm{mM} \mathrm{CaCl}_{2}$. Thromb. Res. 9: 267-276.

32. Gralnick, H. R., and B. S. Coller. 1976. Molecular defects in haemophilia A and von Willebrand's disease. Lancet. 1: 837-838.

33. Kernoff, P. B. A., R. Gruson, and C. R. Rizza. 1974. A variant of factor VIII related antigen. Br. J. Haematol. 26: 435-440.

34. Sultan, Y., J. Simeon, and J. P. Caen. 1976. Electrophoretic heterogeneity of normal factor VIII/von Willebrand protein, and abnormal electrophoretic mobility in patients with von Willebrand's disease. J. Lab. Clin. Med. 87: 185-197.

35. Zimmerman, T. S., J. Roberts, and T. S. Edgington. 1975. Factor VIII related antigen: multiple molecular forms in human plasma. Proc. Natl. Acad. Sci. U. S. A. 72: 5121-5125.

36. Newman, J., R. B. Harris, and A. J. Johnson. 1976. Molecular weights of antihaemophilic factor and von Willebrand factor proteins in human plasma. Nature (Lond.). 263: 612-613.

37. Weiss, H. J., and S. Kochwa. 1970. Molecular forms of antihaemophilic globulin in plasma, cryoprecipitate and after thrombin activation. Br. J. Haematol. 18: 89-100.

38. Rick, M. E., and L. W. Hoyer. 1975. Molecular weight of human factor VIII procoagulant activity. Thromb. Res. 7: 909-916.

39. Zimmerman, T. S., and T. S. Edgington. 1973. Factor VIII coagulant activity and factor VIII-like antigen: independent molecular entities. J. Exp. Med. 138: 1015-1020.

40. Hougie, C., R. B. Sargeant, J. E. Brown, and R. F. Baugh. 1974. Evidence that factor VIII and the ristocetin aggregating factor $\left(\mathrm{VIII}_{\mathrm{RIST}}\right)$ are separate molecular entities. Proc. Soc. Exp. Biol. Med. 147: 58-61.

41. Bloom, A. L., I. R. Peake, and J. C. Giddings. 1973. The presence and reactions of high and lower-molecularweight procoagulant factor VIII in the plasma of patients with von Willebrand's disease after treatment: significance for a structural hypothesis for factor VIII. Thromb. Res. 3: 389-404.

42. Cooper, H. A., and R. H. Wagner. 1974. The defect in hemophilic and von Willebrand's disease plasmas studied by a recombination technique. J. Clin. Invest. 54: 1093-1099.

43. Ratnoff, O. D., C. C. Slover, and M-C. Poon. 1976. Immunologic evidence that the properties of human antihemophilic factor (factor VIII) are attributes of a single molecular species. Blood. 47: 657-667.

44. Barrow, E. M., H. R. Roberts, K. Pons, and J. B. Graham. 1964. Studies of the antihemophilic factor (AHF, Factor VIII) produced in von Willebrand's disease. Proc. Soc. Exp. Biol. Med. 115: 760-763.

45. Bowie, E. J. W., D. N. Fass, J. D. Olson, and C. A. Owen, Jr. 1974. Transfusion and autotransfusion of plasma in von Willebrand's disease. Thromb. Res. 5: 479-494.

46. Fass, D. N., E. J. W. Bowie, C. A. Owen, Jr., and K. G. Mann. 1975. Stability of porcine factor VIII. Thromb. Res. 6: 109-118.

47. Stibbe, J., H. C. Hemker, and S. V. Creveld. 1972. The inactivation of factor VIII in vitro. Thromb. Diath. Haemorrh. 27: 43-58.

48. Kekwick, R. A., and P. L. Walton. 1962. Conditions influencing the stability of human antihaemophilic factor. Nature (Lond.). 194: 878-879. 